\title{
A Project Designed to Examine the Effects that Collaborative Peer Interactions Have on the Professional Development of Teachers
}

Van Holloway

Cedarville University

Follow this and additional works at: http://digitalcommons.cedarville.edu/education_theses

Part of the Secondary Education and Teaching Commons

\section{Recommended Citation}

Holloway, Van, "A Project Designed to Examine the Effects that Collaborative Peer Interactions Have on the Professional Development of Teachers" (2004). Master of Education Research Theses. 4.

http://digitalcommons.cedarville.edu/education_theses/4 


\section{A PROJECT DESIGNED TO EXAMINE THE EFFECTS THAT COLLABORATIVE PEER INTERACTIONS HAVE ON THE \\ PROFESSIONAL DEVELOPMENT OF TEACHERS}

A thesis submitted in partial fulfillment Of the requirements for the degree of Masters of Education

By

VAN BRYCE HOLLOWAY

B.A. Biology, Cedarville University, 1988

2004

Cedarville University 


\author{
CEDARVILLE UNIVERSITY \\ SCHOOL OF GRADUATE STUDIES
}

May 1, 2004

I HEREBY RECOMMEND THAT THE THESIS PREPARED UNDER MY SUPERVISION BY Van Bryce Holloway ENTITLED A Project Designed to Examine the Effects that Collaborative Peer Interactions have on the Professional Development of Teachers BE ACCEPTED IN PARTIAL FULFILLMENT OF THE REQUIREMENTS FOR THE DEGREE OF Master of Education.

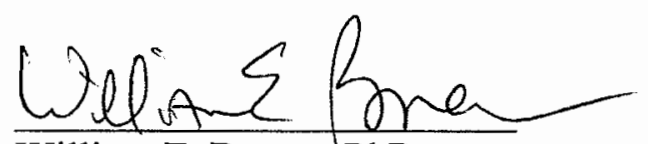

William E. Brown, $\mathrm{PhD}$.

President

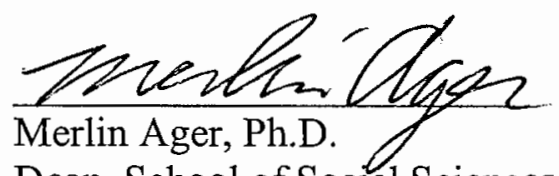

Dean, School of Social Sciences

and Professional Studies

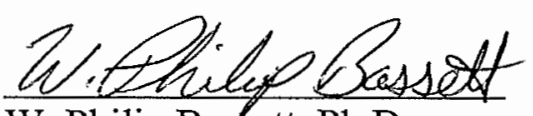

W. Philip Bassett, Ph.D.

Education Department Chair
Wume R. Wood

Dr. Duane R. Wood, D.B.A.

Academic Vice President
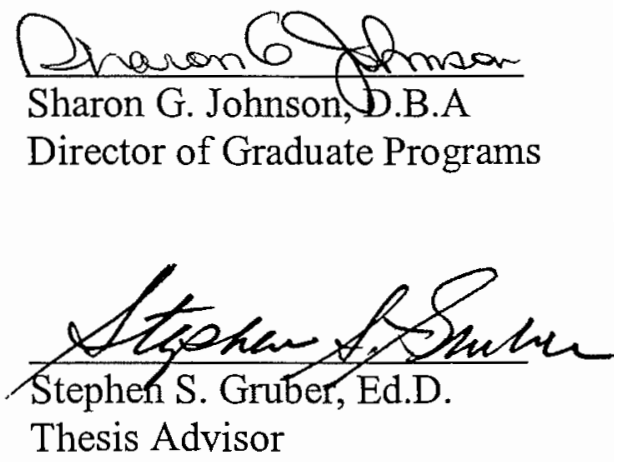


\begin{abstract}
Holloway, Van Bryce. M.Ed. Education Department, Cedarville University, 2004 A Project Designed to Examine the Effects that Collaborative Peer Interactions have on the Professional Development of Teachers

Much research links collaborative experiences to the professional development of teachers. The author of this study designed a project, called the Buddy System, which provided opportunities for teachers to observe one another in the classroom and to interact with one another collaboratively. The goal was to determine if these activities provided a means of professional development. After the implementation of this sixteen-week project, the author collected data from a variety of sources which indicated that professional development had taken place.
\end{abstract}




\section{ACKNOWLEDGEMENTS}

Several very important people have contributed to the success of this project. First, I must thank Robert Colaner and Dr. Phil Bassett who encouraged me to pursue a Master's Degree in Education. The financial assistance from Dayton Christian Schools and from Cedarville University has made this pursuit a possibility. Many thanks are due to both of these outstanding organizations.

I also thank Dr. Gruber for introducing to me the idea of school improvement that can be initiated and sustained by concerned teachers. Understanding this concept helped me to select the topic for this final project. His teaching, advice, and encouragement provided me with the knowledge and support necessary to complete a project of this magnitude.

Without the cooperation and support from the administrators and faculty of Xenia Christian High School this project would not have become reality. My principal, Dr. Alan Geist, consistently believed in my ideas and generously provided the resources to make them happen. My colleagues, the teachers of Xenia Christian High School, were willing to participate heartily in this project. Thank you for your patience, extra-work, and wonderful ideas. Your favorable response to this project has certainly laid the foundation for future teacher-initiated school improvement projects.

I must also thank Dr. Dennis Flentge and many other members of the Math and Science Department of Cedarville University who provided essential resources and encouragement as I worked to complete this project. Having a quiet place to research and write was certainly a major benefit during these last few months of work. Thank you for your generosity.

I have also been blessed to be a part of a caring church family. Thank you my brothers and sisters of Emmanuel Baptist Church for your prayers and concern for my family and me. You certainly exhibited God's love through your hugs, kind words, and helpfulness. Some of you even chose to spend time with our children so that my wife Janell and I could work together on portions of this project. Thank you very much.

Finally, I thank God for saving me through Jesus Christ. Throughout the duration of this project, God has been faithful, powerful, and kind. Thank you God for your continual expression of love in my life. To God be the glory! 


\section{DEDICATION}

This project is dedicated to my wife Janell and our four boys. Janell has faithfully been my helper and support throughout the extent of this project. Furthermore, while working on this project our boys have endured my frequent absences with patience and courage. To my family, thank you for your sacrifices as I have completed this degree. It is wonderful to be home again. 


\section{TABLE OF CONTENTS}

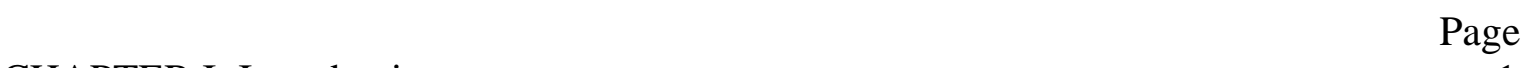

CHAPTER I: Introduction.......................................................

Educational Significance...............................................1

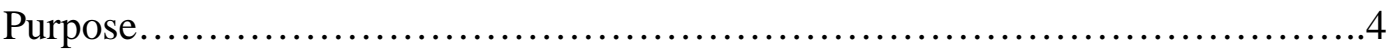

Methodology and Treatment...............................................

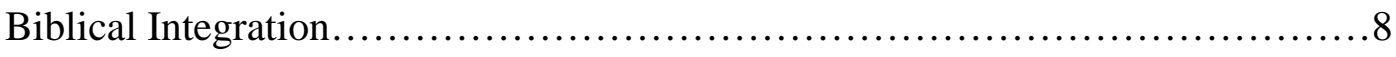

Application.............................................................. 10

CHAPTER II: Review of Literature............................................11

School Culture and Teacher Relations.....................................12

A Case Study............................................................. 14

A Community of Teachers...............................................17

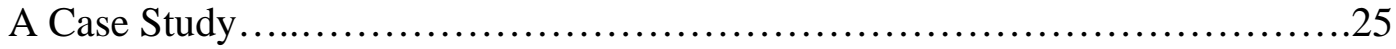

A Case Study........................................................29

Collaboration: The Role of the Principal..................................35

A Case Study.......................................................41

A Case Study ........................................................ 50

Collaboration: The Role of the Teacher...................................56

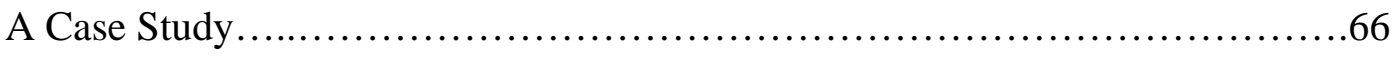

Mentoring: A Transition to Collaboration......................................74

A Case Study....................................................... 78 
Collaboration: A Means to Professional Development and School Reform. 81

CHAPTER III: The Project.................................................84

Project Background..................................................... 84

The Setting........................................................... 88

The Buddy System..................................................88

Project Results........................................................93

CHAPTER IV: Conclusions and Recommendations.................................99

Conclusions.............................................................99

Recommendations.................................................. 101

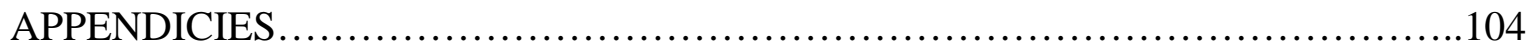

APPENDIX A........................................................ 104

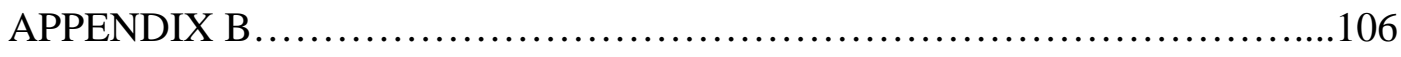

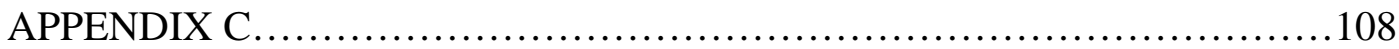

APPENDIX D.....................................................

APPENDIX E.......................................................... 110

APPENDIX F....................................................... 111

APPENDIX G.........................................................

APPENDIX H...................................................... 114

REFERENCES.........................................................115

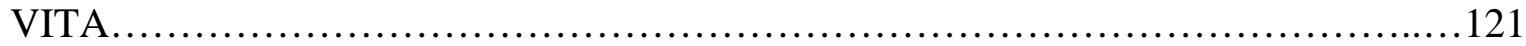

vii 


\section{Chapter I: Introduction}

\section{Educational Significance}

Today, schools in America are faced with a wide variety of situations needing improvement. Educators face problems that range from educating an increasingly diverse student population to understanding the value of conflicting models of theory and practice. Ultimately, the desired goal of any educator must be student achievement. A fundamental piece to this complex puzzle of education involves the professional development of teachers.

Professional development, by its definition, produces better teachers.

Development demands that teachers become learners. Gary Sykes, a professor at Michigan State University concludes that teacher learning must be the heart of any effort to improve education in our society. While other reforms may be needed, better learning for more children ultimately relies on teachers (Sykes, 1996).

Teachers participate in a variety of opportunities for the purpose of professional development. These include such things as workshops, conventions, continuing education opportunities, and personal life experiences. It appears that the current trend in professional development is toward local programs that benefit teachers in their daily practice (Bush, 2003). Inservice training and administrative assistance are two in-school activities that some consider effective in promoting teacher development. Unfortunately, evidence exists that both may be ineffective means of helping teachers to develop professionally. 
A common model for teacher inservice is for the administration to bring in an expert to fix some school problem. Sykes (1996) mixes no words when he describes this form of training as a superficial, faddish inservice education that supports a mini-industry of consultants without improving what goes on in schools and classrooms. Lieberman (1990) adds that teachers, in these workshops, are viewed as the passive recipients of someone else's knowledge. This deficit approach assumes that teachers need information from people in authority. In reality this information is rarely specific enough to connect with the specific needs of teachers. Furthermore, the training that does apply is often quickly forgotten as teachers slip back into the comfortable habits of the past.

Supervisor evaluation and assistance is a second method of professional development frequently offered to teachers. Traditionally principals have been involved in staff development through teacher evaluations. A good principal at the conclusion of the evaluation will leave the teacher with some goals for improvement. However, Kenneth Peterson (2000) in chapter 2 of his book Teacher Evaluation: A Comprehensive Guide to New Directions and Practices states that seventy years of empirical research on teacher evaluation shows that current practices of principal evaluation do not improve teachers or accurately tell what happens in their classrooms. Lortie (1975), who authored a definitive text on education and society entitled Schoolteacher, found that only 7\% of his interviewees saw judgments by their organizational superiors as the most appropriate source of information about how well they were doing. It is difficult to argue that no teacher evaluation should be done. But educators have been content to do the least disruptive activity and call it adequate while sacrificing opportunities for professional 
development. This agreement ignores many important principles of education and means that the benefits of good teacher evaluation will go unrealized (Peterson, 2000). Evidence exists that teacher inservice training and supervisor evaluations are not effective in producing professional development within the school setting. Perhaps the common school culture of isolationism inhibits a natural and powerful source for teacher development.

Roland Barth (1990), author of Improving Schools from Within, argues that a culture of collegiality can break the traditions of the past and unleash unimaginable resources from within the school itself producing what he describes as a "community of learners”. Lieberman (1990) adds that the traditions of privacy and isolation can be replaced by "shared ownership of issues, a willingness to consider alternative explanations for practices and behaviors, and a desire to work together as colleagues”. The workplace for both students and adults will change as a culture of collegiality takes shape. Judith Warren Little (1981) defines collegiality as adults in school who talk about practice, observe each other engaged in practice, work together in curriculum planning, and who teach each other (as cited in Barth, 1990). In effect, collegiality may provide an answer from within a school setting for the professional development of teachers. Sykes (1996) contends that a community of peers serves as an important source of support, ideas, and criticism; and that alternating experiences with reflection is an indispensable force for improving practice. Improved practice is the result of real professional development. If a culture of collegiality where adults are working together can promote staff development from within the school, then how does one get there? 


\section{Purpose}

It is the intent of the researcher to determine if collaborative experiences among teachers will result in a significant increase in their professional development. Along this journey the very culture of the school will be stretched in very uncomfortable, but hopefully productive ways. It is the researcher's anticipation that collaborative practice can effectively lay the ground-work for growing a culture of collegiality. Collaboration, a current buzz-word in education, may provide a link from the traditional school culture marked by isolationism to a culture of collegiality marked by cooperation.

Historically, the culture of teaching has been described primarily as a culture of isolation and autonomy (Lorte, 1975). The traditional organization of the school and the isolation of the teacher within the classroom do not provide the social contexts (Bush, 2003) from which collaborative sharing can occur. Despite the recognized value of collegial sharing, the dominant school structure continues to emphasize teacher autonomy

more than collaboration. For decades, the "cellular organization” of schools has persisted, where teachers expect to teach students without assistance from others (Lortie, 1975). Little (1990) suggests that the reluctance toward involvement in any collective teachergroup stems from fears that such involvement might expose the teachers' autonomic classroom activities to criticism and conflict. It is into a setting such as this that the researcher intends to sow the seeds of collaboration.

Gail Bush (2003), in her recently published book entitled, The School Buddy System: The Practice of Collaboration, provides an excellent description of collaboration. 
Collaboration is goal-oriented talk, discourse, conversation, and communication between two educators. Collaboration not only provides common ground for the educators, but the collaborative process produces multiple perspectives in order to produce innovative outcomes. Collaboration is more than cooperation, for collaborative experiences lead to outcomes that are greater than the partners could have achieved working alone (Bush, 2003). Unfortunately the present school culture often prevents the very fundamental beginnings of collaboration. A few teachers, due to their personality and prior relationships, may be able to collaborate effectively; but the majority of educators are suppressed in isolation. Nevertheless, professional educational organizations are beginning to recognize the powerful influence that collaboration has in teacher development. For example, the National Board for Professional Teaching Standards (NBPTS) includes standards of collaboration in each type of teaching certificate that it offers (Bush, 2003).

Ann Lieberman (1990) cited a study of the "School as a Work Place" by Susan Rosenholtz (1989). In this study Rosenholtz describes schools as being either learning enriched or learning impoverished. Learning enriched schools have collaborative goals at the building level, positive teacher attitudes, principal support of teachers to the point of removing barriers, and support for collaboration. On the other hand, learning impoverished schools have no clear or shared values. Instead they are places where teachers rarely talked to each other, where work is perceived as routine, and where selfreliance and isolation flourish. In the learning impoverished schools, teachers, with no medium for discussion and reflection, retreated to their individual classrooms, and kept 
quiet about their successes and failures. In the learning enriched schools, the opposite was true (Rosenholtz, 1989).

Perhaps professional development resources are closer to teachers than most educational professionals may realize. Collaboration may reduce the need for expert outsiders to come into the schools with their clever solutions. Collaboration may reduce the need for expert supervisors to come down to the teachers with their often ineffective evaluations. If collaboration can take root within schools, perhaps a culture of collegiality will develop and schools from within will become a "community of learners" (Barth, (1990).

This study will focus primarily on developing collaborative experiences among teachers. For this to occur, both teachers and administrators will have to assume unfamiliar roles and responsibilities. Administrators will have to take care to not formalize the life out of professional collaboration. Collaboration, in its purest form can remain spontaneous, voluntary, and grounded in shared goals and commitment (Bush, 2003). Principals will reveal their support of collaboration by providing opportunities and time for teachers to interact (Bush, 2003, Lieberman, 1990). Liberman (1990) noted that all the teachers she studied felt constrained by time--time to both teach and time to work collaboratively with their colleagues. Judith Warren Little (1981) describes the principal as one who states expectations explicitly for cooperation among teachers, who models collegiality by joining with teachers and other administrators, who rewards collegiality by granting release time, space, materials, etc., and who protects teachers who are engaged in collegial behavior (cited by Barth, 1990). As principals support collaboration, the layers of hierarchy with the school will begin to blur. No longer will 
principals be content to have teachers just “do what they are expected to do" and call that staff development. A principal with a collegial mindset will recognize that school is not a place for important people who do not need to learn and for unimportant people who do (Barth, 1990). The extent to which collaborative opportunities occur is directly related to the principal's actions and attitudes that reveal his true evaluation of the worth of collaboration.

Teachers will also be required to assume unfamiliar roles and responsibilities. Current professional development promotes the notion that teachers are responsible for not only their classrooms but for their schools (Bush, 2003). Educators who collaborate have trust and respect for themselves, their students, their colleagues, and their entire school community. Every teacher is to be a staff developer for every other teacher (Barth, 1990). Bush (2003) lends her support to this function of teachers when she adds that goal-oriented collaboration within the school "not only changes the way we work to improve education, it changes the way we think about ourselves as learners”.

\section{Methodology/Treatment}

The researcher intends to undertake a descriptive project designed to provide collaborative opportunities for teachers. Treatments will be based upon research studies and modified to fit the setting. The setting will be Xenia Christian High School located in Xenia, Ohio. This school is one of several campuses of Dayton Christian Schools, Inc. Participants will be full-time Junior High and High School teachers from across every discipline. Initially each participant will be given a survey designed to measure the effectiveness of current professional development opportunities offered by the school. 
As the treatment begins, teachers will be given thirty minutes of time each week during the school day to develop collaborative relationships. An opportunity for collaboration will occur primarily through peer partnering, or as the researcher calls it “The Buddy System”. Peer partners will have opportunities to observe each other in the classroom. Furthermore, time will be provided each week for the partners to analyze and reflect on their observations. It is expected that this phase of peer partnering will begin to break down the walls of isolation and may eventually set the stage for broader collaboration throughout the school. It is also anticipated that the peer partners will work together to provide information that can supplement the principal's evaluation of teachers.

An assessment will be taken after one semester of treatment. The tools for assessment will include a survey of teachers and administrators. Furthermore the researcher will be analyzing written anecdotes made throughout the semester by the teachers and administrators. It may be appropriate to use personal interviews to analyze the perceptions of the administrators and teachers before, during, and after the treatment. Additional assessments are planned for the conclusion of the school year. Raw data will not be available to the public without the consent of the individuals involved. It is the researcher's intent to keep all responses confidential and anonymous to protect the integrity of this project. The goal of assessment will be to determine if collaborative activities have had any significant influence on the professional development of teachers.

\section{Biblical Integration}


The creation account in Genesis reveals God's pronouncement that "it is not good for the man to be alone” (Genesis 2:18, New International Version). Even before sin entered the world, Adam was not complete until woman was created as his "suitable helper”. God's creation was not described as very good until two people were created to live and learn together. Since the very beginning of human existence, God has revealed to us a model for collaboration.

This principle is repeated often throughout the Scriptures. Cooperation is seen in the trinity of God the Father, God the Son, and God the Holy Spirit. Each Person of the trinity has unique responsibilities that blend perfectly to accomplish a single purpose. In John chapters 14 and 17 the work of the Holy Spirit can be characterized, at least in part, as collaborating with the spirit of man. Jesus Christ is nearly finished with his personal ministry on earth as he reveals to his followers the plans of the Father. "But the Counselor, the Holy Spirit, whom the Father will send in my name, will teach you all things and will remind you of everything I have said to you, John 14:26. Jesus speaks again and says, "All that belongs to the Father is mine. That is why I said the Spirit will take from what is mine, and make it know to you.” (John 16:15) Again in the contents of one verse we can see the cooperation evidenced within the trinity and the collaborative work of the Holy Spirit with mankind.

Perhaps the most powerful picture of collaboration in the scriptures is revealed through the imagery used to describe the church as the "body of Christ". I Corinthians 12 provides a beautiful description of collaboration. The concept of uniquely-gifted individuals working together for a common purpose originates with God and should be 
practiced by man. It is truly unfortunate that teachers in schools have been isolated for so long from each other and have missed many opportunities to learn through collaboration.

\section{Application}

The researcher intends that the results of this project be critically analyzed for their effectiveness. Collaboration is a practice that is self-perpetuating, but not always predictable in its course. The power of collaboration is the unexpected. Perhaps just a few pleasant surprises experienced through this project will provide the momentum to explore even more powerful applications of and opportunities for collaboration.

Collaborative relationships are endless. As teachers begin to see one another as valuable resources, perhaps they will begin to recognize other valuable resources with which to partner. Teachers may learn the value of collaborating with supervisors, community resources, university professors, and parents. Furthermore, the peer partnering program, initiated by the researcher, may eventually develop into deeper professional relationships commonly referred to as peer coaching.

As the walls of isolation begin to disintegrate, a culture of collegiality will evolve. This struggle over the very culture within a school will have been worth the effort if it causes teachers to develop professionally. For then students will reap the ultimate benefits as their achievement increases. 


\section{Chapter II: Review of Literature}

In this review of literature, the researcher has by no means exhausted every item of research available on this topic. However, he is confident that the major themes have been sufficiently uncovered and that prominent authors have been cited thereby providing substantial evidence for the claims presented.

People as individuals are amazingly complex creatures, but when studying people and their relationships with others, the complexity magnifies significantly. It has been the intent of this researcher to grasp the potential that collaborative experiences can have in the professional development of educators. However, throughout this study the researcher continued to find that predictable trends are frequently sandwiched between uncertainties. This is due to the fact that unpredictable human beings have unpredictable human relationships. As a reminder of this phenomenon, the researcher has chosen to intentionally scatter "real life” case studies throughout this review of literature. The case studies serve as a reminder to the vast array of collaborative experiences that exist for educators and they often end with surprising results. It is intended that these glimpses into real life will be a reminder to all involved, that God uses a myriad of experiences to make us more complete as human beings. And perhaps complete human beings make the greatest educators. A goal of this research was to uncover the keys to collaboration as a means to professional development, but this proved to yield hauntingly unpredictable answers. Therefore, as a redefined goal, the researcher hopes that this information will motivate educators to continually struggle to find the best avenues of collaboration for 
themselves; for the struggle itself and the outcomes attained promise to result in professional development.

Professional development and personal development are tied closely together, and in some respects seem indistinguishable. Personal feelings and attitudes certainly influence the effectiveness of a teacher. Certainly the success experienced from using an effective pedagogical tool, for instance, can likewise influence a teacher's attitudes and feelings. On the basis of this argument, an effective teacher requires more personal and professional development than most school's are willing or are even able to provide. The researcher, in this document, is using the term professional development to describe all the factors, both personal and professional, that enhance one's ability to teach effectively.

\section{$\underline{\text { School Culture and Teacher Relations }}$}

In schools, relationships between teachers can be placed somewhere in the continuum from being characterized as absolutely autonomous in nature to being characterized as a vibrant community of learners. Teachers within the same school building may hold widely different perceptions as to how they would describe their relationships with colleagues due to a wide variety of personal experiences and needs. Judith Warren Little, in a book edited by Willis D. Hawley, identifies these two diametrically opposed models as the independent artisan model and a teacher learning community (Hawley \& Rollie, 2002). The independent artisan model describes a school that consists of a collection of highly individual but capable teachers, and that supplies its teachers with incentives and resources for the innovations they undertake as individuals. Missing from this model, however, is any provision for moving collectively on school- 
wide priorities or any mechanism for ensuring that all that independent "tinkering" serves the students well. The other end of the continuum is described as a teacher learning community. In a genuine teacher learning community, educators question and challenge ineffective teaching practices and investigate new concepts of teaching and learning. They respect the creative contributions and passions of individuals and maintain an open curiosity about their own practices. Ultimately in a teacher learning community, teachers communicate about the progress of students, develop curriculum or assessments together, and spend time in one another's classrooms (Hawley \& Rollie, 2002).

Traditionally, American schools have been places of autonomy and isolation (Bush, 2003). Lortie’s Schoolteacher: A Sociological Study an authoritative study on the subject of the culture of teaching, confirms this trend. Despite the recognized value of collegial sharing, the dominant school structure continues to emphasize teacher autonomy more than collaboration. For decades, the "cellular organization" of schools has persisted, where teachers are expected to teach students without assistance from others and are assigned specific areas of responsibility (Lortie, 1975). Little (1990) adds that longstanding occupational and organizational traditions supply few precedents; rather, they buttress teaching as a private endeavor. Teachers perceive several advantages to working alone in their classrooms. Some observers maintain that teachers remain behind the classroom door because they can be certain of controlling the work in that domain. Group settings more readily reveal the uncertainties of the classroom. Although the promise of praise and recognition is greater when teaching becomes a public endeavor, so too is teachers' exposure to criticism and conflict. Should teachers, particularly Christian teachers, take such risks? 
The Christian worldview runs headlong against the individualism that pervades our society. Timothy R. Phillips and Dennis L. Okholm, in their book A Family of Faith, write, "We affirm that community life and social institutions are necessary for people to live as image-bearers of God. Being a self-made person is foreign to the Christian worldview. Being a person who can achieve maturity and perfection only in the company of others who are committed to the same project is precisely what Christianity is all about” (Phillips \& Okholm, 2001). Getz (1997) adds that it is impossible to live apart from some kind of human relationships. People do not - and cannot - live in isolation from one another for they are dependent on each other to meet one another's needs - physically, emotionally, socially - and yes, spiritually. Rick Warren, in his widely popular book The Purpose Driven Life states, "We are created for community, fashioned for fellowship, and formed for a family, and none of us can fulfill God's purposes by ourselves” (Warren, 2002). Being a person who can achieve maturity only in the company of others who are committed to the same project is precisely what Christianity is all about (Phillips \& Okholm, 2001). Educators must determine for themselves how the necessity of community will influence the formation of relationships with others within the school building.

\section{$\underline{\text { A Case Study }}$}

Brenda R. Beatty (1999), a professor in the Department of Theory and Policy at the Ontario Institute for Studies in Education / University of Toronto, undertook a study to determine the extent to which a study group could create changes in the professional growth of secondary educators. Eight individuals, including Beatty, met to share 
feelings, perceptions, and professional interests through focused reflection and collaboration. Three to five hour sessions, held usually on Thursdays, occurred once a month over a five-month period. The study group was a heterogeneous group made up of four men and four women ranging in age from 28-52. Furthermore the eight participants represented a full range of academic disciplines from a variety of secondary schools.

Each group member shared in the responsibility of facilitating group discussions that dealt with topics such as Multiple Intelligences, helping students with dyslexia, interdisciplinary thinking and job satisfaction.

Data was collected through interviews before and after the five-month intervention period, questionnaires, journal writings that were submitted voluntarily, and observation notes taken by the author of this study. The quantitative and qualitative data was analyzed in two ways. One way was to look at all of the data for one individual, observe any shifts in perception, and to corroborate any observed shifts from instruments administered pre and post, with final interview data. The second way was to look at the data collectively. Results following the five-month intervention were summarized as follows:

1. All participants reported they found the study group format and the self directionality of the format an important dimension, contributing significantly to their satisfaction in the experience. They suggested that the study group is particularly well suited to professional learning and that professional learning in the supportive context creates a powerfully positive influence on overall motivation.

2. Six of the seven participants assessed by instrument indicated increases in teacher self-efficacy. 
3. All seven participants reported an increase in their perception of their potential within the structure and culture of the organization (school) as it is.

The author of this study mentioned that the isolation experienced by these teachers was what the group helped them overcome, replacing the loneliness and anonymity with being known, appreciate, and accepted. One participant offered: "I feel more motivated having had the opportunity to brainstorm ideas and bounce things off of my colleagues. I am more energetic...It is like iron sharpening iron. The more support and encouragement you can receive from your colleagues, the more we will be motivated. It has helped me a lot.” Another added, “I feel safer, not alone, more confident that I know where I stand...I find myself being a risk-taker in the school, in ways I would never have done before”.

An additional outcome was the formation of interdisciplinary alliances. One participant responded. "Before, I would never have thought of Drama and English relative to my subject, so we're now making games collaboratively, including them in our subject area”.

An obvious limitation to this study, as cited by Beatty, was that the study group was not the only "intervention" in the lives of the participants during the five month period. With this in mind, Beatty did offer a few conclusions to her study of professional development through a study group.

1. Keeping teachers connected to their satisfaction in work is important to keeping schools happy and highly functioning places in which to learn. Doing this well is a challenge to educational leaders and a challenge to the teachers themselves. 
2. All participants reported, in interview, feeling more confident about their ability to be effective in the classroom, and to reflect on that effectiveness. Furthermore, participants reported being "profoundly affected" by the study group experience. They felt freer to experiment, to take risks, and to be creative.

3. Perhaps the most compelling piece of data is that the participants continued to meet in the same style for an additional year beyond the duration of the five month study. This personal commitment certainly weighs in favor as to the value the participants felt the group study provided.

\section{$\underline{\text { A Community of Teachers }}$}

Roland S. Barth, a senior lecturer in education at Harvard University, has written a book entitled Improving Schools from Within. In this text he offers an alternative to the independence and autonomy found frequently in schools today. Barth, (1990) while observing the amazing work of honey bees, suggests "just how great the power of cooperative behavior in the service of a common purpose may be”. Perhaps the answers to many of the problems of schools today can be solved by cooperation, collegiality, and collaboration among those within the schools. Colvin (1996) suggests that with a move toward collaboration, practicing teachers will be jointly responsible for their work in classrooms and their wisdom and experiences will be perceived as professional resources. Lortie (1975) discusses the need for collegial relationships in his chapter entitled “Speculations on Change”. Since teacher individualism and self-selection are still dominant, a need exists for greater adaptability, more effective colleague relationships, 
and more sharing of practitioner knowledge and expertise (Hawley \& Rollie, 2002, Sergiovanni, 1994). Furthermore, every teacher must be considered a staff developer for every other teacher. Barth (1990) comments that school is not a place for important people who do not need to learn and for unimportant people who do. Perhaps a shift in education away from independence and autonomy will lead to a learning community of teachers who are interacting with one another for the goal of increased student achievement. Wineburg and Grossman (1998) link student achievement to teacher learning by concluding that if schools are going to be intellectually exciting places for students they must first be intellectually stimulating places for teachers.

It is now necessary, before inspecting further the scope of collaborative experiences, to analyze more deeply the biblical basis for developing human relationships. In Quaker schools, according to Gerald Cattaro, the head of the Nonpublic Schools Program at Fordham University, the guiding principle for relationships between people is based on the religious belief that every person contains the light of God within him- or herself. Beliefs make a profound difference; they provide a constructive mental mode in which students and faculty may flourish. Beliefs provide an alternative to the competitive mechanisms of most public schools that punish teamwork and collaboration (Bernhardt, Hedley, Cattaro, and Svolopoulos, 1998). In fact, it is belief grounded in faith that pushes schools beyond just offering an education, to ensuring that learning occurs. Faith drives teachers not only to "cover the curriculum", but to create a bridge between the needs of each learner and the attainment of challenging learning-goals (Bernhardt et al., 1990). 
Rick Warren describes in his book real fellowship as unselfish living, honest sharing, practical serving, sacrificial giving, sympathetic comforting, and all the other “one another" commands found in the New Testament (Warren, 2002). The apostle Paul used the Greek word alielon, frequently translated “one another” nearly forty times to instruct Christians regarding their mutual responsibilities to their fellow believers (Getz, 1997). For example, in Colossians 3:12-13 Paul commanded believers to "bear with one another”. It is interesting to note that this command is immediately preceded by words that wonderfully describe the spirit behind the command — compassion, kindness, gentleness, and patience. These qualities are certainly beneficial in developing a collaborative environment in schools. Furthermore, the commands such as "instructing one another”- Romans 15:14, “serving one another”-Galatians 6:2, “caring for one another” - I Corinthians 12:25, and “encouraging one another”- I Thessalonians 4:18 also have application for guiding relationships in schools. In fact, doing what the Bible commands is doing the will of God. Christians have been given the responsibility to redeem their school's culture and begin relating to one another in a God-ordained fashion. Getz (1997) adds that obedience to God is far more than a human process that is based on an act of the will; it's a divine function, as described in Ephesians 3:16-19, where believers draw on the supernatural power of God.

Additionally, the Apostle Paul used the human body as a beautiful example of human relationships between Christians. I Corinthians 12 reveals that these relationships within the "body of Christ" should be characterized by humility, interdependence, and unity (Getz, 1997). Certainly, if Christians are to have a redeeming influence on the relationships with one another at school, these characteristics must be evident. 
Furthermore, Jesus Christ spoke of the relationships of life when he stated, "love the Lord your God...love your neighbor” in Matthew 22:36-40. In Luke 10:25-37 Jesus told the parable of the "Good Samaritan" in response to the question, "Who is my neighbor?” Jesus responded that a neighbor is the one who recognizes that someone else had a need and then responds mercifully toward the needy person. Jesus' command in verse 37 was to "Go and do likewise". Certainly this command of Jesus has relevance for initiating collaborative relationships in schools.

The creation account in Genesis provides the very basis for understanding why human beings must be relational. Relationships are by God's design. It has been true from the beginning of time. When God created Adam, He said, "It is not good for man to be alone. I will make a helper suitable for him”. Genesis makes it clear that the Lord created us to be relational beings (Genesis 1:27, 2:18, 21-24). If nothing else, that is what it means to be made in the image of God. "When God made us in the image of his Trinitarian being, the text specifies that he made us male and female (1:27). That is to say, according to Phillips and Okhom (2001) "to be created in the image of God is to be created a social being; to be fully human the way God intended for us to be is to be a human-in-relationship”. Perfect human relationships were damaged by the fall when man chose to sin. Instead of living in love and harmony, enmity and malice has entered our relationships. This is evident in Cain's response to God just a short time after the fall, “Am I my brother's keeper?” The prevalent attitude in our culture today has not changed one bit, we still refuse to be our brother’s keeper (Phillips \& Okholm, 2001).

It is time to reform the culture of schools and not just the practices found within schools. Perhaps these principles from scripture will give courage and hope to the one 
who wants to break down the walls of isolation in their school and see the creation of opportunities for building relationships one with another. Professional development of this type will not only bring surprising benefits to the students, but also encouragement and hope to the very soul of each educator who chooses to value relationships with their colleagues as God intended them to be.

Many researchers agree that teachers are most effective when they are able to experience internal satisfaction with the work they do. Any professional development strategy that a school chooses to implement must take this into consideration. Michael Koehler and Jeanne Baxter (1997) have written a book entitled, Leadership through Collaboration: Alternatives to the Hierarchy which suggests that morale in any school is highest when teachers can satisfy their own needs as they contribute simultaneously to the normative values of the school. Teachers feel good about themselves and their jobs when their needs are met while they meet the needs of their students. The satisfaction of such needs constitutes the essence of teacher motivation. The strongest incentives for teachers derive their power, according to Lortie (1975), from enabling teachers to reap psychic, intangible benefits from making a difference in the classroom.

Career satisfaction for teachers hinges on the ability to pursue the personal values and beliefs that led them into teaching - to be of service and to make valued contributions to young students (Lieberman, 1988). Teachers, who feel they are moving, who feel a sense of continuing challenge and growth, generally aim for more, try harder, and express a high level of commitment to their organization. Common goals, collegiality, a problem-solving orientation, membership in a professional group that focuses on the improvement of practice, and the exercise of teacher leadership all contribute to enhanced 
morale and performance (Leiberman, 1988) and should be considered in every professional development plan. Michael Fullan, Dean of the Ontario Institute for Studies in Education of the University of Toronto, is recognized as an international authority on educational reform. In his book entitled Leading in a Culture of Change, Fullan (2001) adds that most people, not just educators, want to be part of their organization; they want to know their organization's purpose; they want to make a difference. When the individual soul is connected to something deeper there is a strong desire to contribute to a larger purpose.

Few teachers have the opportunity or the desire to advance to administrative positions, therefore the opportunities for personal advancement of this type are limited (Lieberman, 1988). Teaching can be seen as a career with opportunities as long as teachers are able to see themselves developing professionally. Advancement to them is becoming a better teacher, not moving up in their career to another position. Teachers, then, conceive of career and define career satisfaction largely in subjective terms making a difference and sharing a discipline they love. Advancement is framed in terms of an ongoing process of professional growth, and success means effectiveness in the teaching role.

Lieberman (1988) suggests two important pieces, in creating a culture where teachers are able to internally motivate themselves toward excellence through professional development, level of opportunity and level of capacity. Level of opportunity is the chance to develop basic competence; the availability of stimulation, challenge, and feedback about performance; and the support for efforts to try new things and acquire new skills. Such opportunities, Lieberman continues, may include things as workshops, 
conferences, inservice activities, mentoring relationships, sharing ideas with other teachers, observing other classes and being observed, changing subjects, schools, or grade levels, and collegial interaction. Teachers with rich opportunities to grow and learn tend to be enthusiastic about their work and are motivated to find ways to do even better. In contrast, teachers with low levels of opportunity become burned out, just make it through the day and wind up feeling stuck in dead end jobs with nowhere to go in terms of their career.

Level of capacity is the second piece, according to Leiberman (1988), necessary for creating a professional culture in schools that is able to shape a teacher's sense of career and satisfaction. Capacity comprises teachers' access to resources and the ability to mobilize them, the availability of the tools to do their job, and the capability to influence the goals and direction of their institution. Schools may include teachers in decision making processes and curriculum choices or just offer sufficient books and other tools of the trade. Teachers with a sense of capacity tend to pursue effectiveness in the classroom, express commitment to the organization and career, and report a high level of professional satisfaction. Lacking a sense of power, teachers often end up just "coping” by lowering their aspirations, disengaging from the setting, and framing their goals only in terms of just getting through the day.

In short, research suggests that the greater the participation of teachers in decision making, the greater their productivity, job satisfaction, and organizational commitment. Many teachers will lead if given the opportunity. Lieberman (1988) concludes that teacher-leaders derive respect from other teachers for their efforts and they derive energy 
from leadership activities, which fuels, rather than depletes, their classroom activities. Is this not a powerful and often neglected means of professional development?

A school environment that promotes a satisfying career, first of all, provides a resource-adequate environment that provides the minimum tools and conditions necessary to teaching. Second, an integrated school environment is characterized by unity of purpose, clear organizational guidelines and goals, and a collective sense of responsibility. Third, satisfied teachers thrive in a collegial environment that provides multiple opportunities for interaction and creates expectations of colleagues as regular sources of feedback, ideas, and support. A collegial environment enhances both level of opportunity and level of capacity for teachers, because it serves as a critical and essential source of stimulation and motivation. Fourth, careers and professional satisfaction is enhanced by an environment that is problem-solving rather than problem-hiding. A problem solving environment is characterized by a strong sense of group purpose that encourages teachers to reflect on their practice and explore ways to improve it. Finally, an environment that promotes individual opportunity and capacity is investment-centered rather than payoff-centered. Teachers are rewarded for growth, risk taking, and change rather than only for successful past practice (Lieberman, 1988).

Beyond the opportunities of professional development that are created in the environment previously described, an effective professional development program will provide teachers with very specific skills necessary to meet the special needs of the learner. Teachers who have access to teacher networks, enriched professional roles, and collegial work feel more efficacious in gaining the knowledge they need to meet the complex needs of their students (Bernhardt et al., 1998). In light of this information, staff 
development with the greatest potential for helping teachers will be found in a culture of collaboration where teachers are encouraged to share knowledge with each other.

\section{$\underline{\text { A Case Study }}$}

Margarita Calderon, a research scientist with the Center for Research on the Education of Students placed at Risk, John Hopkins University has written an article entitled "Teachers Learning Communities for Cooperation in Diverse Settings" (Calderon, 1999). This article highlights some of the best practices and precautions learned from diverse collegial efforts among educators in El Paso, Texas, and Juarez, Mexico. During the years of 1988-1998 research was conducted to understand the effectiveness of a collaborative program entitled "Teacher Learning Communities". This study was based on the notion that if children from diverse backgrounds are to succeed in schools, then teachers, also from diverse backgrounds, need to learn to work together effectively and efficiently.

It has been projected that by 2010, Latino students will become the largest minority group in U.S. schools, therefore bilingual school issues will continue to remain in the forefront. The richness of diversity in a faculty must be acknowledged as a powerful resource in dealing with these difficult issues. The author of this study states that in effective schools, professional development must be viewed as a collegial structure that facilitates the implementation of a dynamic program constantly under review and improvement. 
In this study, these structures were called “Teachers Learning Communities” or TLC's. TLC's provided time within the workday during which teachers got together to analyze school improvement efforts, share accomplishments, exchange instructional strategies, and set up peer coaching relationships. These heterogeneous groups were described as a community of teachers working together toward success in teaching and student learning. The key to success in these groups hinged on the ability of teachers to cooperate with each other. The richness of diversity in a faculty was acknowledged as a powerful learning tool. Space was created where the individual talents of each teacher could emerge. Teachers learned to let go of their fears and invited each other to observe their classroom instruction. TLC's provided the flexibility to allow teaches to invent personalized strategies to suit their particular needs.

Some schools had weekly TLC meetings that usually began with teachers sharing their greatest success of the week. Several activities followed including assessment of lesson plans, student work, or school issues. Teachers modeled successful strategies for each other, read and discussed journal articles, and brought problems to solve. TLC's provided a context for bilingual and mainstream teachers to work and learn together. Often these forty-five minute sessions ended with a celebration of someone's birthday or some other happy occasion.

Other schools scheduled a two-hour monthly meeting for the TLC's to meet. A few of the schools in this study also provided an early release day for teachers to meet together in teams or in a school-wide session.

Two valuable tools were developed by teachers through their TLC experiences. The first was the widespread use of exemplary team teaching. The second was the use of 
ethnographies in a peer coaching format. For example, while one teacher taught in one language the other completed a language use survey. Then after reversing roles, teachers were able to study their teaching behaviors and language usage. One interesting note was that teachers who expected to use Spanish and English equally in their bilingual classrooms were actually using English nearly 65\% of the time.

Some conclusions have been suggested by the author of this ten-year study. An amazing 95\% of the teachers reported that creating bonds and relationships was the most important first step in reform. Several teachers and administered reported that this was the first time they began to care about their peers, particularly those from different ethnic backgrounds or philosophical perspectives. Cooperative learning strategies were effective in helping teachers feel safe discussing controversial issues. Teachers Learning Communities, this study suggests, led to professional development and reform in schools with rich cultural diversity by providing the time necessary for educators to build trust and share valuable discourse.

The professional development opportunities available to new or new-to-thebuilding teachers may be an important place to begin when examining a school's professional development strategy. According to the National Commission on Teaching and America’s Future, Urban Initiative Partner Newsletter, about one-quarter of new teachers leave the profession within the first three years of teaching. Nationwide, about thirty percent leave within their first five years, and in urban areas about half leave the profession within five years (Curran \& Goldrick, 2002). As discussed previously in this 
document, teachers who leave the profession are most likely to do so because of a personal dissatisfaction with their work. An effective induction program will provide the professional and instructional support that new teachers need. These needs typically include developing collaborative relationships with colleagues; handling the demands and expectations of students, parents, and the school community; and providing assistance with teaching practices, instructional strategies, and course materials. Mentoring and release time are often cited as two of the most critical components of an induction program (Curran \& Goldrick, 2002). The following is an example of a school district that has proactively focused its professional development on the needs of new teachers. Karen Beerer who is supervisor of Curriculum and Federal Programs for the Quakertown Community School District has authored an article entitled, "District Carves out Time for New Teachers to Learn”. In this article Beerer (2002) explains that the key to effective staff development for new teachers is time. In Quakertown, new teachers spend an additional fifteen contractual days each year during their first five years of teaching in a comprehensive New Teacher Academy, in addition to being mentored their first year. During these fifteen days each year, new teachers take part in workshops specifically designed for them. One third-year teacher in the district teacher expressed his appreciation, "One of the main reasons I chose Quakertown was because of its commitment to professional development. I taught in three schools before Quakertown, and each of them basically gave you a one- or two-day orientation, and then you were thrown into the classroom to sink or swim". Another teacher added, "It is wonderful to be treated like a valuable asset. Thanks! I love it here already." When teachers, such as 
these in Quakertown, feel confident, prepared, and supported, there is bound to be a positive effect on students and their learning.

Curran and Goldrick (2002) suggest that not only do good induction programs improve teacher retention, but they influence teaching practices, increase teacher satisfaction, and promote strong professional development and collegial relationships. But schools should not just focus all their professional development energies onto new teachers. Sustained professional development must be available for all teachers, from their induction to their retirement (Colvin, 1996).

Sustained professional development, particularly through collaborative experiences, involves the cooperation and participation of both principals and teachers (Lieberman \& Miller, 90). As schools shift from a culture of isolation to collaboration, principals and teachers will have to assume new and often uncomfortable responsibilities. The researcher will first examine the role of the principal in creating a collegial environment where collaboration leads to exciting and often unexpected forms of professional development.

\section{A Case Study}

"In the Company of Colleagues: An Interim Report on the Development of a Community of Teacher Learners” provides an excellent evaluation of a professional development project that sought to establish a community of learners among high school teachers (Thomas, Wineburg, Grossman, Myhre, \& Woolworth, 1998). Several highly qualified researchers selected a large, multiethnic, urban high school for their work in 
establishing the Community of Learners Project. This project initially brought together nine members from the high school English department, five members from the high school history department, four student teachers, a special education teacher, an English as a Second Language teacher, and the team of five university researchers. This learning group met together twice each month, once after school, and once for an entire school day during the two year project. A research grant provided funds for the necessary substitute teachers and most of the meetings were held at the local university.

The goal of the project, according to the research team, was to forge a community of teacher learners that included the full range of teachers, from student interns to department chairs. The project designers worked under the premise that professional development was better achieved through a sustained community of learners rather than through individual efforts. By drawing on each individual's private understandings, the researchers hoped that the collective understanding of the group would be advanced.

Group discussions, with the belief that individual contributions are taken to levels that no group member could attain individually, provided the primary means of interaction. The researchers envisioned three avenues of discussion. The first centered on reading books together. Texts were proposed and selected by the participants themselves, and included works of history, fiction, and memoirs. A second activity during meeting times involved the work on a new interdisciplinary humanities curriculum that combined the resources of all participants in the project. By the end of the second year relatively few curricular materials were completed, but many discussions from the meetings surfaced in the teacher's classrooms. The final activity for the community of teacher learners was the interdiction of a video-club. This was designed by the 
researchers to have teachers video taped in their classrooms and then each teacher would present a short evaluation of their teaching to a group of three of four colleagues.

This research study was guided by the following four questions: 1) How does intellectual community form among high school teachers? 2) How does the formation of a community of learners provide opportunities for teachers' learning of subject matter, pedagogical content knowledge, student understanding, and curriculum development?

3) How do teachers learn from colleagues?

4) What do teachers at different stages of their career take from participation in a community of learners?

Some of the forms of data used to measure results included interview transcripts, questionnaires and surveys, and self-report documents from the participants. The interim report of this study outlined the impact that a community of learners had on experienced teachers, new teachers, specialists, student teachers, and finally on the research team.

Experienced Teachers. The experienced teachers (having more than ten years of experience) reported feeling alone for most of their teaching career. One teacher, a 30 year veteran, commented, "In this building, in all frankness, as in most buildings, we're closeted, compartmented, both within and between departments”. However, after two years of participation in this project the experienced teachers reported a new appreciation for their Community of Teacher Learners experience. An experienced English teacher described her positive experience in the Community of Teacher Learners when she added, “I’m struck again, and again by how much more I’ve felt connected to my colleagues than I ever felt before... I feel more connected to my job because of this”. Another experienced teacher responded that he found it refreshing "to have these 
discussions and be treated professionally...many of us feel that we frequently are not treated as professionally as we should be treated”.

The researchers noted that a few experienced teachers excused themselves from certain projects and some even dropped out of the study altogether due to frustration and conflict. The authors of this study believe this was due to the fact that collaboration invariably engenders conflict and the community provided a venue where pre-existing conflicts surfaced in a public form. However, for those who continued to participate, the project provided the group the time necessary to become sensitive to differences and to explore how these differences can be negotiated with favorable results.

New Teachers. The first or second year teachers entered this program with a general feeling of being isolated, neglected, and somewhat anonymous to the rest of the staff. Instead of finding a clear hierarchy in the group’s structure and process, the new teachers found a growing willingness for everyone to draw on their collective understandings that emerged through shared discourse. One new teacher commented, “It's exciting to me that I've been able to learn from people that I work with and I think that they've learned some things from me...it puts our whole relationship on a different level”. Another new teacher assumed a degree of leadership and became a strong proponent for expanding this learning community model to other teachers and relationships within her school. It is apparent that the Community of Teacher Learners provided substantial support for the new teachers.

Specialists. The specialists who participated in this program appreciated the opportunity to take part in the broader discourse within the school and to heighten the awareness of the special needs students among all teachers. Two years of project 
meetings definitely increased the level of collegiality between specialists and the regular teachers. One special education teacher took a strategy from the project meetings to her classroom. She commented that "the kinds of things that I've posted around the room about supporting claims with evidence, we talked about these things very specifically, about listening, about building on others' comments, about questioning each other”. Another specialist, who shared some strategies from her classroom with the community, was excited to learn that an experienced member of the English department started to do some of the same strategies in his classes.

Student Teachers. The student teachers entered this project feeling incompetent about sharing ideas or even about asking questions. They felt further restrictions due to the uncertainty of their futures and the need for a good recommendation from a cooperating teacher. Quickly however these feelings dissolved as they participated in the Community of Teacher Learners. One student teacher appreciated a project activity that provided her with the means of learning how to teach critical reading. Another commented on the variety of pedagogy that she observed within the group. The learning group also benefited as the student teachers eagerly contributed to the group's reading agenda by suggesting text that they encountered at the university. The researchers concluded that the student teachers established themselves as a conduit between the academy and the school in ways not easily available to the research team.

University Research Team. The researchers played a unique role in creating and sustaining the Community of Teacher Learners. One obvious obstacle that the research team had to overcome was the provision of time and space for the teachers to come together. Ultimately, the researchers determined that time and space was their most 
effective contribution to the community. Furthermore, as the study progressed, the researchers faced another obstacle-conflict. Opportunities for conflict arose periodically as a group of teachers, accustomed to independence and privacy, made their opinions and beliefs public. As outsiders to the teaching community, the researchers were able to assume the role of mediators by establishing working norms of professional civility. Additionally the researchers constantly had to evaluate their dual role as participant/observer. Often the researchers' vision for professional development was not in sync with the teachers' vision. In some instances, the research agenda was out of touch with the level of trust found within the group. This became evident as only one “video-club meeting” occurred. The researchers had hoped that the video club would provide the teachers with a chance to examine the connection between teaching and student understanding, but from the teachers’ perspective the videos were “intrusive devices that carried with them the taint of evaluation”. The researchers admitted that they had underestimated the time needed to establish a professional culture that was receptive to peer feedback and critique. They concluded that they have become more cognizant of the time, effort, and trust that underlie efforts to reform the professional culture of teaching.

These researchers hope to do further research to see how these professional development activities impact the classrooms; for students are the ultimate measure of effectiveness. However, it is apparent that the greatest differences can be made only when teachers have a sustained opportunity to come together and explore issues of teaching and learning; and these opportunities take time. The researchers who conducted this study conclude that it will take both commitment and courage to provide teachers the 
time they need for professional development through a project such as a Community of Teacher Learners.

\section{Collaboration: The Role of the Principal}

Principals and other school leaders have an important responsibility to ensure that teachers develop professionally. If professional development is expected to come through teacher collaboration, some of the traditional roles of the principal will need to be modified. Fundamentally, collaboration is an alternative value system that consists of noncompetitive cooperative behavior, nonhierarchical networks and processes, and a displacement of power from the top to the center (Bernhardt et al., 1998). The principal is certainly a key element in the school's focus and vision; however, the process of creating and proclaiming the central insight that guides a school through its daily responsibility of educating children should be an experience shared by everyone. This is the essence of collaboration, to coalesce the broad range of skills that operate in every school in order to develop and sustain a vision, then to cooperate to assure its achievement (Koehler \& Baxter, 1997).

Therefore an effective principal must be willing to relinquish personal power, so that the latent, creative powers of the teachers can be released (Lieberman, 1988). Lieberman (1988) and Chubb and Moe (as cited in Bernhardt et al., 1998) suggest that this transition of leadership may be more difficult in public schools which tend to be characterized by deep rifts between the teachers and the administration. Smyth (2001) adds that some school leaders can and do use teacher isolation - the very antithesis to 
collaboration - as a very effective means of protecting their own power. Parochial schools, however, may have a distinct advantage in instituting collaborative transformation. Parochial schools, Lieberman (1988) observes, often operate under what is often referred to as "servant leadership" on the part of the principal. Here the principal leads adults by serving adults. This invariably means involving teachers in important school decisions. It is difficult to serve teachers by excluding them.

One method that principals can use to foster collegiality is to incorporate teachers in the decision making processes at school. Barth (1990) suggests there is probably no more fertile, demanding, and satisfying place for collegiality in schools than in sharing responsibility for important decisions. How leaders in schools distribute this ownership has a huge influence on the capacity of a school to improve from within. Effective principals should not, when a problem emerges, quickly reach a solution and then invite a teacher to "handle" the situation. This Lieberman (1988) warns is an opportunity for maintenance, not teacher leadership. The energy, fun, and commitment around leadership come from brainstorming one's own solutions and then trying to implement them. The litmus test of all leadership is whether it mobilizes people's commitment to putting their energy into actions designed to improve things. It is individual commitment within a context of collective mobilization (Fullan, 2001). Leadership, then, is not mobilizing others to solve problems which principals already know how to solve, but is helping teachers confront problems that have never yet been successfully addressed. In this sense, the principal's leadership success will not be measured by who he is as a leader but by the leadership he produces in others (Fullan, 2001). 
Lieberman (1988) suggests some practical strategies for principals as they begin to promote a collaborative culture in their school. Principals must remember to share in the responsibility for failure. The important issue is not whose fault it is but what happened, what can be learned from it, and how it might be done better next time. A principal who stands behind a teacher through failures has hope for developing collegiality, staff development, and morale. Secondly, effective principals must remember to reflect all success onto their teachers. School-wide success has the dynamic ability to replenish the teachers personally and professionally. Lieberman (1988) concludes that the best principals are not the heroes; they are the hero-makers.

Another important task of the principal that is closely associated with professional development is the evaluation of teachers. In a collegial environment principals will be required to accomplish this task from a new and perhaps uncomfortable position. Historically, schools were designed after military and government models. The hierarchy that resulted created variable levels of authority to coordinate the growing numbers of teachers and activities within the schools. It also resulted in variable levels of status and decisional input, the highest levels enjoying the most status and exercising the most decisional input regarding the character of education's programs and culture (Koehler \& Baxter, 1997, Bernhardt et al., 1998). Principals were assigned a position of authority over the teachers.

The principal's ability to effectively evaluate teachers remains suspect. Lortie (1975) found that only 7\% of the teachers he interviewed saw judgments by their organizational superiors as the most appropriate source of information about how well they were doing. Kenneth Peterson (2000), who has conducted extensive research in 
teacher evaluation, concludes that seventy years of empirical research on teacher evaluation shows that current practices of evaluation do not improve teachers or accurately tell what happens in their classrooms. Part of the difficulty faced by principals is that there are so many variations of a good teacher. To add complexity to this issue, one article identified the following ten characteristics of good teachers: Ideal teachers meet standards set by school principals, supervisors, and education professors. Analytic teachers use observation techniques to record how well they are meeting their instructional intentions. Effective teachers bring about higher student achievement. Dutiful teachers perform assigned teaching duties well. Competent teachers pass tests that indicate they possess requisite teacher attributes. Expert teachers have extensive and accessible knowledge and can do more in less time. Reflective teachers examine the art and science of teaching to become more thoughtful practitioners. Satisfying teachers please students, parents or caregivers, colleagues, supervisors, and administrators. Diversity-responsive teachers are sensitive to all students. And respected teachers possess and demonstrate qualities regarded as virtues (Cruickshank \& Haefele, 2001). Considering this vast spectrum of desirable qualities, the task of a principal is enormous when evaluating teacher performance.

Koehler and Baxter (1997) offer even less hope as they describe the principal's work as documenting something they can not really prove, about someone they do not really know, to someone who really does not care. Additionally, Peter Drucker, a management consultant quips "there is nothing so useless as doing efficiently that which should not be done at all” (Koehler and Baxter, 1997). 
John Smyth vividly describes the dominant form of teacher evaluation as social control that endorses authoritarian notions of pedagogy. Smyth continues his assault by adding that evaluation practices are trying to separate goals from practice. Teachers are encouraged to facilitate already identified goals, rather than to debate them. (Smyth, 2001). This perspective sets the traditional form of teacher evaluation in complete opposition to the principles of teacher leadership and collaboration.

It is difficult to argue that no teacher evaluation should be done. The corrupting contract among educators is to do the least disruptive activity and call it adequate. However, this treatment ignores many important principles of education and evaluation and means that the benefits of good teacher evaluation will go unrealized (Peterson, 2000). A principal faces new responsibilities when tackling teacher evaluations within a climate of collegiality.

Koehler and Baxter (1997) suggest that the responsibility for evaluation be shared between the administration, peers (colleague group), and by teachers themselves. This strategy would be consistent with the belief that teaching is not an individual act - it is a social, relational, and interactive process that depends for its success on notions of sharing and community (Smyth, 2001). In this perspective, the principal becomes a facilitator of teacher evaluations from multiple sources. President Wilson once said, "One cool judgment is worth a thousand hasty counsels. The thing to do is to supply light and not heat”. Koehler and Baxter (1997) add that the principal should promote the illumination that comes from teacher self-assessment and avoid the heat that comes from traditional evaluation. 
Koehler and Baxter (1997) provide some practical questions that must be considered by a principal or any individual during a teacher observation for the purpose of evaluation.

1. Is the purpose of the observation to provide anecdotal and objective feedback to the teacher for purposes of self-evaluation, or is it to document teacher performance for evaluative/employment purposes?

2. Who is to conduct the observation and what kinds of data are to be gathered?

3. How will these data be gathered?

4. Who will analyze these data to determine implications?

5. Who will use the analyses to make value statements about the quality of teacher performance?

A collegial environment can be achieved if a principal is willing to discuss these questions with and among teachers prior to an observation and evaluation.

Furthermore, four practical steps are provided by Koehler and Baxter (1997) for principals when conducting a post-observation interview with a teacher.

1. The principal interprets and analyzes the data

2. The teacher receives the data before the post-observation conference

3. During the meeting time the principal seeks to elicit analysis from the teacher and discusses the teacher's reactions

4. The principal makes a written record of the teacher's self-evaluation It is important to note that value judgments should only be made by the teacher and not by the principal. It takes time to break down the preconceived notions of evaluation, but when principals begin to promote self-evaluations among their teachers, evaluation has 
just moved closer to professional development. When teachers are treated as a member of a professional learning community, it is obvious to see the principal's role shift from authoritative to facilitative.

Moreover, as principals lead schools in a collegial direction, their relationships with and evaluations of teachers must be marked by trust. Principals must remember that teachers have traditionally been considered subordinate to administrators. Teachers and principals, when interacting, must remember the following truth: "Until I can risk appearing imperfect in your eyes, without fear that it will cost me something, I can’t really learn from you" (Koehler \& Baxter, 1997). Trust is an essential ingredient in powerful relationships that enable professional development. Trust builds the foundation and the willingness to promote teacher self-evaluation. The ability of teachers to be observed and, later, to discuss their observations in non-threatening and objective ways is directly proportional to the ultimate success of the evaluation (Koehler \& Baxter, 1997, Weasmer \& Woods, 1999). Principals must allow teachers the freedom to remake, and if necessary re-order, the world in which they and their students live (Smyth, 2001). In this context, the principal is not losing control of the evaluation process, but instead is sharing the control.

\section{$\underline{\text { A Case Study }}$}

Anthony S. Bryk and Barbara Schnieder conducted a longitudinal study for nearly a decade of more than four hundred Chicago elementary schools. A summary of their findings were published in an article entitled "Trust in Schools: A Core Resource for 
School Reform” (Bryk \& Schnieder, 2003). These authors spent time observing school meetings and events; conducting interviews and focus groups with principals, teachers, parents, and community leaders; observing classroom instruction; and talking to teachers about the progress and problems in their reform efforts. Mathematics and reading scores were also statistically analyzed as a measure of student learning. By linking evidence on the schools' changing academic productivity with survey results on school trust over a long period of time, Bryk and Schnieder were able to document the powerful influence that such trust plays as a resource for reform.

According to the authors of this study, relational trust was grounded in the social respect that came from the kinds of social discourse that take place across the school community consisting of exchanges among students, teachers, administrators, and parents. Respectful exchanges were marked by genuinely listening to what each person has to say and by taking these views into account in subsequent actions. An interrelated set of mutual dependencies were rooted within the social exchanges in any school community and all participants remain dependent on others to achieve desired outcomes. Such dependency created a sense of vulnerability and therefore steps should be taken to make each participant feel safe and secure through the building of relational trust.

Personal regard represented another important criterion in this study for determining how individuals discern trust. Such regard sprang from the willingness of individuals in schools to extend beyond the normal responsibilities of their "job" description. Personal regard was evident as the researchers visited one particular school. The authors noted that "almost every teacher we spoke with at one school commented effusively about the principal's personal style; his openness to others; and his willingness 
to reach out to parents, teachers, and students”. His efforts helped cultivate a climate in which such regard became the norm across the school community. This climate, in turn, was a major factor in the high level of relational trust found in this most unexpected place - a 100 percent low-income, African American population in a school serving a public housing project, with a white, male principal.

This study revealed the correlation between relational trust and effective schools. In schools where professionals trusted one another and sensed support from parents, they felt safe to experiment with new practices. Similarly, relational trust seemed to foster the necessary social exchanges among school professionals as they learned from one another. Talking honestly with colleagues about what's working and what's not meant exposing one’s own ignorance and becoming vulnerable. Further evidence revealed that relational trust supported the imperative to take on the difficult work of school improvement. As these authors noted, most teachers worked hard at their teaching. When implementing 'reform' these teachers assumed risks, dealt with organizational conflict, attempted new practices, and took on extra work, such as engaging with colleagues in planning, implementing, and evaluating improvement initiatives.

Additionally, the researchers found that elementary schools with high relational trust were much more likely to demonstrate marked improvements in student learning, while a school with a low score on relational trust at the end of the study had only a onein-seven chance of demonstrating improved academic productivity. Half of the schools that scored high on relational trust were in the academically improved group. On average, these improving schools recorded increases in student learning of 8 percent in reading and 20 percent in mathematics in a five-year period. Most significant was the 
finding that schools with chronically weak trust reports throughout the period of the study had virtually no chance of improving in either reading or mathematics.

This study revealed that relational trust was more likely to flourish in small elementary schools with 350 or fewer students where social networks are typically fewer in number. Larger schools tended to have more limited face-to-face interactions and more bureaucratic relations across the organization. Furthermore, the principal's actions played a key role in developing and sustaining relational trust. Effective principals acknowledged the vulnerabilities of others, actively listened, and exhibited a consistency between words and actions. Bryk and Schnieder concluded that good schools depend heavily on cooperative endeavors. Relational trust is the connective tissue that binds individuals together to advance the education and welfare of students. Improving schools learn how to best organize the work of adults and students so that this connective tissue remains healthy and strong.

Principals and other school administrators, who are often responsible for inservice and workshops, generally consider them to be effective forms of school-wide professional development. However statistics reveal that these forms of professional development have been tragically ineffective. A survey done by Peter Lipman in 1991 determined that only five to eight percent of teachers transfer a professional development session into action (as cited in Beatty, 1999) Furthermore, workshops tend to be one-shot presentations that are rarely integrated with other aspects of the school's professional growth program (Wineburg and Grossman, 1998). Rarely do teachers get follow-up 
opportunities to practice what someone else has preached. Rarely do schools provide comprehensive professional growth activities that enable teachers to functionally integrate the ideas of visiting experts. It seems that many in-service programs serve only to satisfy state-mandated expectations and to impress the local parent community (Koehler \& Baxter, 1997).

Eleanor Perry, in her article entitled, “Collaborative School Improvement: An Integrated Model for Educational Leaders” describes traditional staff development as experts conducting one-day seminars on current educational issues, strategies, or instructional methods. Sometimes teachers became trainers-of-trainers by presenting a staff development sessions for their colleagues, however, administrators rarely initiate professional full-staff growth efforts (Perry, 1997). Gary Sykes, a professor in the Department of Education Administration and Teacher Education at Michigan State University, adds his criticism by describing the "one-shot workshop" as shorthand for superficial, faddish inservice education that supports a mini-industry of consultants without having much effect on what goes on in schools and classrooms (Sykes, 1996). Wineburg and Grossman (1998) conclude that any presentation that speaks equally to the diverse interests of the calculus teacher and the gym teacher, the French teacher and the physics teacher, will almost certainly be marginally effective. Generic workshops are easy to dismiss because many teachers believe--rightly or wrongly--that the strategies covered do not apply to their subject matter.

Koehler (1996) proposes that if inservice was intended to help teachers grow professionally, teachers would not be "lectured at" once every two or three months. Instead principals should provide teachers with opportunities to learn the concepts and 
integrate them into their instructional repertoires. School leaders must consider the value of local, problem-based approaches to professional development that are built into teachers' ongoing work with colleagues (Bernhardt et al., 1998). The planning of insevice activities can be a natural avenue by which a principal can elicit the collaborative participation of teachers. Teachers can be given the opportunity to work together to select the in-service themes, identify the sources of instruction, practice with colleagues what they have learned, and evaluate the outcomes to see if the concepts have been integrated and implemented (Koehler, 1996).

In summary, effective principals are to create in their school a culture that considers professional development as something that evolves from within teachers and not something that they need to do to teachers. Hence, the principal is not a provider of professional development, but instead facilitates an environment where teachers are able to develop professionally. Stephanie Pace Marshall (as cited in Beatty, 1999) uses the metaphor of a living organism to depict the principal's role for creating this change. In living systems, growth is found in disequilibrium, not in balance. Leaders in educational transformation are not to seek to eliminate disequilibrium from their schools, but to regulate it, so that growth can emerge naturally from within their schools.

To enhance the environment in which collaboration grows, the principal must practice several important skills. For example, the skills of observing, evaluating, and directing need to be supplemented with the skills of listening, questioning, probing, and guiding (Ash and Persall, 2000). Additionally, when change occurs, there will be disturbances, and this means that there will be differences of opinion that must be reconciled. Fullan, (2001) advices that effective leadership means guiding people 
through the differences and, indeed, enabling differences to surface. Leaders should strive to create a culture that reduces the fear of change and implements organizational processes that promote innovative practice (Ash and Persall, 2000) and risk taking. The teacher will not become a leader of the school community if, when the going gets tough and the angry phone call comes from a parent, the principal violates the trust and reasserts authority over the issue (Lieberman, 1988).

Margaret Johnson, assistant to the chairperson of the Department of Curriculum and Instruction at Southern Illinois University and Gregory Johnson suggest five strategies for principals that have guided the collaborative culture of Carbondale Community High School in Carbondale, Illinois. Destratify. All teachers must enjoy the same privileges and hardships. No one should bear the brunt of poor schedules or feel isolated due to perceived or real inequalities. Administrators must be on the watch for inequities and ready to even them out. Empower. Teachers must collectively make their own decisions concerning curriculum and instruction. Ownership is essential to success. Collaborate. Teachers should be encouraged to work together on many projects, such as redesigning and evaluating curriculum and student assessments, planning instruction, and developing and delivering staff development activities. Unfetter. Teachers must have genuine opportunities to work together. They need time to discuss ideas and work on projects. They also need a place to meet, like a lounge area or conference room, where they can be comfortable and productive. Recognize. Much of a teacher's reward for working successfully in these ways is intrinsic. However, external rewards complement and encourage further growth. Newspaper articles, for example, can recognize teacher efforts and student accomplishments. Principals may also provide classroom release time 
for staff development and monetary compensation for non-school time spent in staff development activities (Johnson \& Johnson, 1999).

Ash and Persall (2000) conclude that the principal must create an environment that supports collaboration among teachers; provides time for teachers' professional development; and recognizes, rewards, and celebrates the concept of the teacher as leader. Emihovich and Battaglia (2000) add that the best thing that a principal can do for his teachers is to find creative ways for them to spend time together. Teachers need time, other than lunch, to collaborate. In fact, many researchers agree that the most difficult obstacle facing collaboration is time. Time, time, time, (Donaldson and Sanderson, 1996, Wineburg, et al., 1998) must be provided for teachers. Time is essential; blocks of intensive work may be more productive than several short meetings, but principals, above all, must ensure that teachers have productive time together. Successful collaboration depends on people willing to commit their time to a task and to a colleague they value. Many teachers who are suddenly expected to participate in the collaborative activities tend to perceive such involvement as an imposition on their time and a diversion from essential classroom activities. If reluctant teachers, such as these, are adequately compensated for the additional time necessary, Koehler and Baxter (1997) suggest that they will tend to become less resistant to collaborative changes.

Bush (2003) cautions school leaders to not formalize the life out of professional collaboration. Collaboration, in its purest form, is spontaneous, voluntary, and grounded in shared goals and commitment. Furthermore, leaders must recognize that an immediate squelching of collaboration will take place right from the beginning if teachers are not involved in the initial steps of collegial planning. Administrators who unilaterally create 
programs, and then impose them on the staff, have no sense as to the heart of collegiality. Principals interested in implementing such programs without involving teachers from start to finish run the risk of failure or, more likely, of only marginal success. Teachers, right from the start, need to learn data-gathering techniques and conferencing skills and must have the opportunity to practice them. Schools interested in implementing collaborative programs must involve teachers in the initial planning activities by conducting needs assessments, by being sensitive to the problems that confront teachers in the classroom, and by listening to the suggested solutions. Koehler and Baxter (1997) conclude sharply that the administration's attempt to lessen the impact of the hierarchy by unilaterally introducing a collaborative program only affirms the hierarchy's power by failing to plan and implement the program collaboratively!

Ash and Persall (2000) suggest that action research be used by principals to introduce and sustain collaboration in their schools. Action research, they describe, involves implementation of innovative practices and assessment of the results of those practices. Establishing a climate of trust, eliminating the fear of failure, and encouraging innovation are actions principals must undertake to encourage staff participation and control in each step of action research. Effective schools find ways to link collegial activities with every aspect of administrative detail, from identifying problems to evaluating solutions.

Good administrators provide a nurturing work environment and promote growth by satisfying the fundamental needs of teachers: their needs for recognition, a sense of accomplishment, feelings of autonomy and competence, and increased responsibility (Koehler \& Baxter, 1997). In this sense, school leaders provide learning opportunities for 
the faculty and staff so they can develop into productive leaders (Ash \& Persall, 2000). Innovative solutions often come from teachers who do not know how to do it but want to learn how. The moment of greatest learning is when teachers seek out assistance to resolve problems that they care about desperately. This is the dynamic intersection of teacher-leadership and professional development (Lieberman, 1988).

Great administrators recognize the potential of their staff and will overcome significant obstacles to provide collaborative learning opportunities. Some of these obstacles are considered in an article entitled, "Creating a Community of Learners among High School Teachers” (Wineburg, et al. 1998). Releasing teachers from the classroom once a month creates bureaucratic hassles, scheduling snafus, and grading crunches when meetings fall at the end of the semester. After-school meetings conflict with cheerleading practice, soccer games, or simply getting home to make dinner. Some meetings sizzle with new ideas and stimulating conversation and others will sputter to a stop. Real progress in education does not come neatly packaged for display in bar charts and growth-lines, but is similar to making meaning from a Faulkner novel, a process filled with switchbacks and blind curves, ultimately satisfying but long in coming (Wineburg, et al. 1998). Principals need the courage to allow teachers the time and the space to come together in a community of their peers. It is a simple yet radical solution to professional development.

\section{$\underline{\text { A Case Study }}$}


Judith Haymore Sandholtz, the author of this study, is an assistant professor in the School of Education, University of California, Riverside, where she directs the Comprehensive Teacher Education Institute. The study (Sandholtz, 2000) compared various approaches to team teaching for student teachers at the high school level. Team teaching was defined as joint planning, joint instruction, and joint evaluation. The primary goal was to provide for the student teacher's professional development through collaboration, experimentation with new teaching strategies, observation of colleagues, and collegial analysis of instruction. The results of this study have been documented in an article entitled, "Interdisciplinary Team Teaching as a Form of Professional Development”.

Data for this investigation, which was collected over a period of five years, drew from four primary sources: questionnaires, interviews, observations, and group discussions. Both student teachers and cooperating teachers participated in the evaluation of the team teaching strategy. Data was collected and analyzed on a yearly basis so that changes toward increasing the effectiveness of team teaching could be implemented the following year. The following is a description of the chronological evolution of the team teaching program as directed by Sandholtz and her project management team.

First Year. When team teaching was first implemented, the student teachers were organized into pairs within the same subject area and cooperating teachers were instructed to take a hands-off approach in hope that the student teachers would take more ownership of the class and implement their own teaching strategies. In sequence with the University's schedule, the student teachers entered the classrooms immediately after spring vacation. Data collected from the student teachers at the conclusion of the team 
teaching experience was widely varied. One student teacher responded, "Stellar. Working with the other student teacher has been an absolute delight...With the appropriate person, I would love to team teach again. The key is the person you work with...and we were able to get together after school to meet”. Another student described the experience as "Hellish. It was apparent that we were not welcome there as a team. From my perspective, the cooperating teacher did not want to relinquish that class”. A third response reveals the typical low-level collaboration that developed through team teaching. "My partner and I have very different teaching styles. But we have worked out a good system where she takes one aspect of teaching and I do another aspect...I wouldn't say it was so helpful that it would make me a better teacher”. For this team, collaboration was more a sharing of responsibilities than cooperative planning and instruction. When asked to evaluate the program, half of the teachers suggested either making team teaching optional or eliminating it all-together. Additionally, cooperating teachers felt concerned for relinquishing their class so late in the year and this feeling was magnified by the hands-off approach they were asked to take.

Ranking the overall team teaching experience on a four-point Likert scale (1=poor, 4=excellent), student teachers responded to this initial experiment with a mean of 2.44 .

Second Year. The project management team made several changes in the team teaching program for the second year. Cooperating teachers were asked to be advisory members of the teaching team. This meant that cooperating teachers would be involved in the planning and evaluation, but not in the instruction. Another change was the formation of some teams of three student teachers (triads) and some interdisciplinary 
teams. Furthermore, team teaching was introduced earlier in the university class schedule and more planning time was scheduled into the student teacher's schedule. Responses collected at the end of this second year of experimentation were once again not overwhelmingly favorable. Student teachers described it as a practical experience that allowed them to share teaching responsibilities and try new approaches with students. One student, a member of an interdisciplinary team, responded, "The good part is that it is extremely valuable in exposing you to another discipline”. Another commented, "I actually see her teaching and we learn from each other-strengths and weaknesses...It is neat getting to see how somebody else would go about teaching something”. When evaluating the worth of team teaching most students suggested shortening the program or moving it earlier in the year to avoid their busy late-spring schedules.

Ranking the overall team teaching experience on a four-point scale (1=poor, 4=excellent), student teachers responded to this second year experiment with a mean of 2.66.

Third year. With two years of mixed results, the project management team decided to make team teaching an option for student teachers. Early in the second semester many students were enthusiastic about the idea of team teaching and many believed that the experience would be advantageous. However, as the semester progressed and the pressures on the students increased, no student teachers opted to complete a team teaching assignment. Data collected at the end of the semester did, however, reveal some interesting information to the management team. More than half of the student teachers regretted not doing team teaching and suggested that it should be a requirement. One student shared this opinion, "I think it would be nice to work with 
someone else...so though you may not be team teaching outside of student teaching, you'd still know how to work with somebody else”.

Fourth year. Several changes were implemented by the project management team including instituting team teaching as a requirement for student teachers.

Furthermore, cooperating teachers, at their own suggestion, became full team members involved equally in all aspects of the team teaching. Another major change was the formation of mostly triads consisting of one cooperating teacher and two student teachers; and these triads where mostly interdisciplinary. Several benefits to these changes were immediately obvious. Cooperating teachers no longer felt threatened to give up their classes late in the school year. In fact cooperating teachers reported that the team teaching experience was a benefit for themselves, their students, and for the student teachers. When asked to describe the impact on their students, one cooperating teacher responded, "Students gained confidence...Team teaching is a positive method of working with students. Each team member brings to the students their unique and usually effective way of relating curriculum to the class being taught”. As cooperating teachers noticed the favorable impact that team teaching had on themselves, their student teachers, and on their students, they requested that the team teaching program be retained. Project managers also observed that the interdisciplinary teams provided an opportunity to draw on the strengths of experts and thus altered the typical expert-novice roles. Student teachers noted the value of collaborating with other teachers and learning about another discipline. 
Ranking the overall team teaching experience on a four-point scale (1=poor, 4=excellent), student teachers responded favorably to this fourth year experiment with a mean of 3.46 .

Sandholtz, when considering the evolution of this program, offered some suggestions to consider when designing team teaching for the purpose of professional development. It was beneficial to include cooperating teachers as full team members. This enabled them to have a sense of control over their classroom and a greater ability to influence student teachers. The teams of three (triads) worked very well to reduce personality conflicts and it provided a softening to the cooperating teacher as "expert" role. Interdisciplinary triads provided student teachers with the opportunity to be experts in their respective disciplines. Having equal roles in which all team members are involved in planning, instruction, and evaluation provided an excellent opportunity for colleagues to work on a joint task. Sandholtz concluded that equal roles promote central goals of team teaching such as collaboration, experimentation, and collegial analysis of instruction. Interdisciplinary team teaching proved to be a natural way to decrease expert-novice distinctions and facilitate equal roles and responsibilities.

Curriculum development arose as an unexpected benefit of this experiment. Since cooperating teachers were not already involved in interdisciplinary instruction, team members had to develop curriculum and methods that combined their disciplines. This promoted greater collaboration among team members and created a situation in which they were all novices in a sense.

A major burden to team teaching was finding the right time and enough time to collaborate. This team teaching program provided the necessary time for planning and 
reflection by altering the master schedules to provide common planning periods for each team member and also by encouraging teams to meet together after school.

As Sandholtz looked back over the growth of this team teaching project she provided the following summary. "With a sense of advantages for themselves and their students, both cooperating teachers and student teachers viewed team teaching less as an increased workload and more as a valuable component of the program”. Even though interdisciplinary team teaching was not an original goal in this experiment, it proved to be an effective means for providing professional development of both student teachers and their cooperating teachers.

\section{Collaboration: The Role of the Teacher}

An examination of the roles and responsibilities that teachers have when given opportunities to collaborate will now be made. Gordon Donaldson, Professor of Education at the University of Maine and Coordinator of the Maine Network of School leaders, has coauthored a book entitled, Working Together in Schools: a Guide for Educators. Three basic arguments for collaboration are suggested. Collaboration among teachers provides direct benefits for the children, provides direct benefits for educators, and provides professional enrichment of the school's culture (Donaldson \& Sanderson, 1996). As teachers prepare to embark on a journey to this new environment that promises such powerful outcomes, it is important to review some key descriptions of collaboration. 
Collaboration is defined as a style for direct interaction and communication between at least two coequal parties voluntarily engaged in shared decision making as they work toward a common goal (Friend \& Cook, 2003, Bush, 2003). The power of collaboration lies in its ability to achieve greater goals than either individual could have achieved alone. This occurs because the collaborative process invites divergent thinking and multiple perspectives in order to produce innovative and unique outcomes. Furthermore, collaboration is a mysterious process that involves redirecting the path along the way, therefore the results are by definition unpredictable and often unintended (Bush, 2003).

Collaboration grows best in what Barth (1990) describes as a collegial environment. Judith Warren Little defines collegiality in schools as adults talking about educational practice, adults observing each other engaged in educational practice, adults working together in creating, testing and evaluating curriculum, and adults teaching each other what they know about teaching, learning, and leading (as cited in Barth, 1990). Barth (1990) adds that teachers who work together and are engaged in important school decisions develop collegial relationships. Collegiality is more than just "getting along" in school; it involves adults who recognize that success depends on the depth of their relationships.

It does not take an observant teacher long to realize how difficult it is to meet the very diverse needs of learners. Recent studies of cognitive learning reveal that learning is much more complex than originally thought. Learning was once thought to be straightforward, simple acquisition of facts and skills while teaching was a straightforward, simple delivery, performance, and technical/humane service (Lieberman, 
1988). If collaboration has the potential to provide answers to these and other difficulties faced by teachers every day, then perhaps teachers should develop collegial relationships.

It is important to recognize that any tool of professional development, including collaboration, can be used inappropriately thereby rendering it ineffective. Teachers, bound by tradition, may resist the depth of interaction with their colleagues that is necessary for collaboration. Some may say "it's not my job" to be an active inquirer who creates and shares knowledge with colleagues (Emihovich \& Battaglia, 2000). Furthermore, the initial attempts at collaboration may produce few obvious products. Emihovich and Battaglia (2000) describe collaboration as fragile work that is often crushed by the weight of other seemingly critical agendas and, unless collectively supported, risks disintegrating all together. Additionally, positive results of collaboration are not guaranteed. Strong communities can make matters worse if, in their collaboration, teachers (however unwittingly) reinforce each other's bad or ineffective practice (Fullan, 2001, Little, 1990). This is why close relationships are not ends in themselves. Fullan (2001) warns that collaborative cultures, which by definition have close relationships, are indeed powerful, but unless they are focusing on the right things they may end up being powerfully wrong. Furthermore, innovations created by collaboration, or for that matter any other means, will prove disruptive and ineffective if they are implemented as another disconnected and piecemeal project.

Judith Little (1990), in her article entitled "The Persistence of Privacy: Autonomy and Initiative in Teachers’ Professional Relationships” recognizes two reasons why teachers may be resistant to the establishment of collaborative opportunities. The first is that school-teaching has endured for years largely as an assemblage of entrepreneurial 
individuals whose independence is grounded in norms of privacy. Teachers are content to do what has always seemed to work just fine. In fact experienced teachers tend to discount the negative effects of isolation and to weigh carefully the cost of investing greater resources in time together with other teachers. To them, the teacher-student relation is at the heart of schooling.

Little (1990) suggests a second reason why teachers may resist collaborative changes. Some teachers already recognize some existing activities as collaboration and do not see the need for change. For example a teacher may cite story telling as a collaborative exercise that already exists frequently in the staffroom. Teachers may gain information and assurance in the quick exchange of stories, but this casual exchange is often distant from the classroom. Little (1990) is skeptical that brief stories told of (not in) classrooms could advance teachers' understanding and practice of teaching. Under such circumstances, storytelling as the dominant or exclusive mode of teacher interaction probably serves to sustain rather than to alter patterns of independent practice.

Others may claim that when a teacher asks another for aid and assistance that this constitutes a collaborative activity. Little (1990) cites research that claims that teachers carefully preserve the boundary between offering advice when asked and interfering in unwarranted ways in another teacher's work. Most teachers expect to supply advice when asked--and only when asked. The brevity of these interactions, as described here, certainly will have little effect in creating a culture of collegiality.

Finally, teachers may claim that working together regularly in groups is collaboration. Formal groups may exist for grade levels and department meetings or for completing a specified task. Again, Little (1990) asserts that these groups are rarely able 
to effect substantive change. Instead individuals in these groups are typically concerned about the loss of individual latitude to act on personal preferences--or to act on personal preference unexamined by and unaccountable to peers that is required for effective collaboration. When teachers feel they can achieve success and satisfaction independently, their motivations to participate substantially with one another are weakened. As suggested, important attitudes and behaviors are missing from the previously discussed activities which keep them from being truly collaborative in nature.

Marilyn Friend and Lynne Cook (2003), in their text Interactions: Collaboration Skills for School Professionals, provide an excellent description of collaboration. The term collaboration conveys how the activity is occurring, that is, the nature of the interpersonal relationship occurring during the interaction and the ways in which individuals communicate with each other. Teachers may have opportunities to work in close proximity, but only the individuals involved can decide if a collaborative style will be used in their interactions. Collaboration requires parity among the participants. Parity is a situation in which each person's contribution to an interaction is equally valued, and each person has equal power in decision making. It is important to understand that teachers may have parity as they work together on a specific collaborative activity even though they do not have parity in other situations (Friend and Cook, 2003).

The extent to which teachers are willing to collaborate with each other is related to their personalities and prior relationships with colleagues. Furthermore, attitudes toward teaching, teaching workload, and family obligations all may shape a teachers' disposition to forge close ties with their colleagues (Bush, 2003, Hawley \& Rollie, 2002). These conditions will determine the effort necessary to build trust, the essential 
component of collaboration. Educators who collaborate have trust and respect for themselves, their students, their colleagues, and their entire school community. Trust is necessary to overcome the reluctance to share with others. Only after a period of time in which trust, and subsequently respect, are established can school professionals feel relatively secure in fully exploring collaborative relationships. Trust is able to overcome the fears that teachers have of exposing their beliefs and practices for examination, and potential criticism, of a collective group. Trust is an essential component of collaboration (Bush, 2003, Friend \& Cook, 2003, Walker, 1999).

Additionally, trust is only established with time. In a chapter entitled, "What Matters Most”, Rick Warren (2002) in his book suggests that the importance of things can be measured by how much time one is willing to invest in them. The more time one gives to something, the more one reveals its importance and value. Time is the most precious gift that one can give because it is finite. A person can make more money, but not more time. Time, when given to another in a collaborative setting, represents a portion of one's life that can never be gotten back.

“A Time to Talk”, by Robert Frost

WHEN a friend calls to me from the road

And slows his horse to a meaning walk, I don't stand still and look around On all the hills I haven’t hoed, And shout from where I am, What is it? No, not as there is a time to talk. I thrust my hoe in the mellow ground, 
Blade-end up and five feet tall,

And plod: I go up to the stone wall

For a friendly visit.

William Bennett (1993) adds this editorial comment to the poem, "Work always calls us. But we make time for friends when they call us too”.

Teachers, who take the time to collaborate, must exercise certain skills. One fundamental skill is the art of reflection. Before a thought can be shared with another, the teacher must first acknowledge the thought to himself (Bush, 2003). St. Francis of Assisi, in his famous prayer, asked God to help him to "seek first to understand, then to be understood" (Buzzell, 1998). Reflective teachers examine their own practice of teaching and seek a greater understanding of teaching. Experience and learning are not the same. In order to learn from experience, one must think about it and make sense of it, and that is reflection (Lieberman \& Miller, 2001, Cruickshank \& Haefele, 2001). A community of peers serves as an important source of support, ideas, and criticism; this combined with alternating experiences with reflection is an indispensable impetus for professional development (Sykes, 1996).

Effective collaboration cannot be discussed without mentioning the importance of communication in sustaining collegial interactions among teachers. God forewarned Isaiah to expect communication problems throughout his ministry. Isaiah 6:9 states "Go and tell this people: 'Be ever hearing, but never understanding; be ever seeing, but never perceiving'." Buzzell (1998), the general editor of the Leadership Bible comments that the people would hear God's message, yet they would not understand it. They might allow God's words to pass briefly through their conscious minds, but they would not 
permit those words to take hold in any meaningful way. Verse ten reveals the outcome of true understanding, "they might see with their eyes, hear with their ears, understand with their hearts, and turn and be healed” (Isaiah 6:10). Buzzell (1998) concludes that the purpose of communication is neither to speak nor to listen, but rather to achieve greater understanding between people.

Donaldson and Sanderson (1996) in their comprehensive text, suggest that effective collaboration requires both listening skills and influencing skills. Listening skills involves paying careful attention, striving to understand, and helping to clarify. Good listeners try to understand another rather than evaluate their opinions, suggestions, and behavior. This is often accomplished by restating what has just been heard and checking to see whether the restatement is accurate. Teachers who wish to be good listeners cannot assume that they understand until they have asked the question, "Is this what you mean?”

Influencing skills, the second ingredient for effective collaboration, involves our ability to speak for ourselves, say where we stand, and disclose otherwise hidden thoughts and feelings. Good influencers are able to identify when it would be helpful to make a contribution, speak straightforward from the heart, and share insights and judgments with others. Good influencers desire to enrich the collective understanding of what is being done. Listening and influencing skills should enable teachers to share ideas in accepting and non-threatening ways and in essence, to collaborate effectively within a culture of collegiality (Koehler \& Baxter, 1997).

Collaborating teachers also must be responsible for the way they use words in their communication. Words can be used as either a weapon that destroys or as a tool 
that builds. The Bible vividly describes this phenomenon. The apostle James described the tongue as a "restless evil, full of deadly poison” (James 3:8) while Proverbs 16:24 states, "Pleasant words are a honeycomb, sweet to the soul and healing to the bones". Getz (1997) suggests that words can have a powerful healing effect on both the soul/spirit and the body. Each individual educator has this power in his words to mightily strengthen or to seriously damage the bonds of trust and the forces of collegiality within their school.

One of the most frequently mentioned skills needed by teachers when engaging in a successful collaboration is the ability to deal with conflict (Walker, 1999). Disagreements will arise over the very basic issues of teaching and learning. Teachers will be faced with the tricky divide between "making a suggestion" and "telling someone what to do”. Jealousies and resentments surrounding individuals or groups and inadequate knowledge will add stress to the process. Sometimes it seems the best hope is that working with colleagues will be at least as effective as working alone (Hawley \& Rollie, 2002).

Friend and Cook (2003) outline the various responses that individuals may have toward conflict. The first four are usually harmful to collaborative efforts. The first response to conflict is the competitive style. This is the "win at all cost" strategy. This strategy is only desirable when ethical or moral issues are at stake. The second harmful response is the avoidance style. This produces the "all is well” perception. Avoiding problems temporarily may enable the individuals involved to think about their positions and participate more constructively, but ultimately discrepancies must be faced. The third response to conflict is the accommodative style. This occurs when teachers set 
aside their own needs for the sake of agreement. This can be beneficial when the issue is relatively unimportant or when the situation cannot be altered. The fourth response to conflict is the compromising style. This produces a "give and take" strategy that results in outcomes that are not perfect, but may be acceptable to all. Friend and Cook warn that competitive individuals, when asked to compromise, often consider it a personal defeat. This may delay, but certainly not resolve conflict. Additionally, the results of compromise may be disappointing for all. For example, if one person wanted an east coast vacation, and the other person a west coast vacation, by compromising they would end up in Kansas!

The best method of dealing with conflict, according to Friend and Cook (2003), is with the Collaborative Style. By working together, teachers can often develop a completely new alternative to resolve the conflict situation. These authors again warn that this approach is time-consuming and it can only be undertaken as professionals learn about and come to trust one another.

In chapter 9 entitled, “Dealing with Conflict and Frustration: Acknowledge Your Limits”, Donaldson and Sanderson (1996) in their book describe three potential sources of conflict (obstacles) and propose solutions for each. Teachers meeting together as a group for collaborative purposes will likely face external obstacles such as the school schedule, space, or even the administration. In this situation it is important to remember to include the principal in the communication loop, to work around the obstacles and not to take them on directly, and to start with small, working relationships.

Teachers may face a second source of conflict categorized as internal obstacles. Teachers sharing together will face differences of opinion, style, and philosophy. It is 
suggested that teachers learn to be more tolerant, patient, flexible, receptive, and less judgmental when dealing with these obstacles. Collaboration often causes a teacher to confront just those aspects where one most needs to grow. Furthermore, teachers must be alert for frustration arising from differences and deal with them before they become major conflicts.

The third and final source of conflict is the obstacles of personal energy teachers are simply too busy. These authors propose that collaborative tasks be taken on slowly and only after each participant has communicated their commitment. Collaboration is only beneficial if it is more personally and professionally rewarding to a teacher than working alone. Teachers should devote time to individual needs and concerns and just enjoy being together. Teachers are more likely to make time for collaboration if it becomes a personally rewarding and satisfying experience.

The very nature of collaboration requires that the group learn to confront the conflicts that inevitably arise as the community emerges. Teachers must interact directly with colleagues they may previously have chosen to avoid. They must confront the different perspectives about subject matter and teaching that dwell in the same hallway. The process is not easy or comfortable, but, as one teacher put it, it is "painfully necessary" (Wineburg \& Grossman, 1998).

\section{$\underline{\text { A Case Study }}$}

Azita Manouchehri, author of this case study, is on the faculty of the mathematics department at the University of Texas-Pan America where she works with graduate and 
undergraduate mathematics and mathematics education students. Her areas of research include teacher change and development, problem-based mathematics learning and teaching, and mathematics teacher preparation. This qualitative case study of two pairs of middle school mathematics teachers was designed to develop an understanding of the distinctive contributions that teacher peers make in the process of improving teaching. This study was intended to answer the following three questions:

1) How is collegial interaction carried out among a team of teachers?

2) What aspects of teachers' work are most affected by peer collaboration?

3) What do colleagues learn from each other and how is that knowledge manifested in their practice? (Manouchehri, 2001).

The research was conducted in a Midwestern public school district serving six hundred middle-level students. The mathematics teachers involved were in the first year of implementing a reform-based textbook. These teachers were granted one hour of release time each week and also additional release time once a month to observe each other's teaching and to collaborate. The principle data collection techniques used were participant observation and informal and semi-structured interviews with the teachers. Data was collected over a period of seven months.

Julie and Doug, two sixth grade mathematics teachers made up the first team of teachers. Both of the teachers in this pair were in their mid-twenties, with Doug having a slight edge in teaching experience. Julie was not formally trained in mathematics and admitted that she had a lot to learn about teaching math. She stated, "I know that I really don't have the mathematics background of the other teachers...my major was social studies and I just love teaching math so I decided to do it...I want somebody to come to 
my class, observe my teaching, and then tell me what I am doing wrong”. Julie viewed Doug as an enthusiastic colleague and a good friend with whom she felt comfortable sharing teaching ideas.

Doug, on the other hand, had a high reputation for being a good mathematician. He had a tendency to try new things in the classroom, but if the results were not immediate he quickly abandoned them. Doug did not see the teaming process as something that he could particularly benefit from himself, but as a means to help Julie. When asked about Julie he commented, "She takes teaching so seriously...She is so organized all the time...last week she wanted us to sit down and talk about a project we plan to do next month!...Would you believe it? She is just too serious”.

The second team of teachers, Ben and Gary were both veteran teachers with more than twenty-five years of experience. These seventh-grade mathematics teachers were pleased to be chosen to work together on this project. Ben was known in the school as "the man most liked by the students". He saw his role as an entertainer or even a nurturer as he constantly attempted to connect with his students on a personal level. Even though Ben’s teaching style was different from his partners, he respected Gary for having taught high level math for a long time before moving down to the seventh grade. Ben anticipated learning a lot from the teaming practice including having an opportunity to learn what Gary was doing in class and taking time to prepare and implement more cooperative learning activities for his students.

Gary, the most senior mathematics teacher in the district, had reservations about the effectiveness of the new curriculum. In the classroom he was calm, soft spoken, and showed tremendous respect for his students. Gary took pride in helping his students to 
develop the fundamental skills necessary for a further study in mathematics. He also hesitated to use hands-on activities when the same results could be obtained in a shorter amount of time through a well-planned presentation. Gary had no specific goal for this partnering study; he just wanted to learn how to use the new text and to make it work in class.

At the conclusion of this study it was determined that physical proximity did not naturally provoke intellectual collaboration. Indeed, when left without specific guidelines, standards, or expectations; three of the four teachers gained little from peer interaction. The author of this study concluded that the teachers needed to learn how to engage in collaborative reflection on both self-practice and peer-practice in ways to improve teaching and to facilitate teacher growth.

Manouchehri, in this case study, discovered from the pairs two very different responses to the collaborative opportunities provided during the seven months. Ben and Gary's observations and feedback were nonspecific, very informal, and had a lack of coherence. Even though several opportunities were available to provide critical feedback to each other, Ben and Gary rarely discussed academic issues in depth. For instance during a typical team planning time, following a five-minute exchange of a "description" of what each person intended to do in class, the conversation quickly moved to social talk about sports or current events.

It was apparent that in spite of their differences in how they implemented the same lesson, neither one was influenced by, or tried to influence, the activity of the peer. In essence, their observations of one another and subsequent discussions contributed to the development of stronger beliefs about the appropriateness of what they did in their 
own classes. This can be seen in Ben's comments on Gary's teaching, "You see how he does not let the kids talk a lot in class...It is not because he does not care for the kidsHe really does. But I will never do what he does—after what I saw I am even more convinced that I should let the kids talk”. Although Ben and Gary shared instructional materials, they were hesitant to convince one another as to the validity of their own selected strategies and styles. The author of this case study concludes that the collegial proximity for them did not contribute to refinement of peer practice but to a self-reflexive action. Observation and feedback or critique of one another's teaching did not appear to be a natural part of their professional lives.

Julie and Doug began their interactions in a way that was very similar to Ben and Gary at the beginning of the school year. Julie and Doug exchanged stories of the events of the classroom. Doug regularly listened to Julie's situations and he saw himself as an emotional support for her. Doug stated, "I think the best thing I can do for her is to listen to her stories...I don’t think that I can really solve the problem for her-after all, each class and each student is different. What works for me may not work for her--, so most times I just listen”. Julie, meanwhile, was searching for deeper professional interactions and seeking specific pedagogical solutions. Julie’s frustrations can be sensed when she stated, "I guess I want more-it is so good to have someone that you talk to and say, hey, I am really frustrated about this—-When I came out of class yesterday and I asked Doug about a student's problem, I was hoping he would give me a different perspective—I was hoping he would say 'try this or that' but he did not”. Doug's personal reflections and observations of Julie's teaching continued to be far too informal and general to satisfy Julie’s urge for learning. 
Finally, the author of this study notes, there was a change in orientation. In October as Doug had planned to visit Julie’s classroom, Julie asked him to collect specific data on particular students. Furthermore, she asked Doug to write down the various questions she used in class because she was interested in improving her questioning technique. Doug obliged and the discussion that followed this observation required Doug to not only reflect on his teaching, but also to assist Julie in recognizing important aspects of her instruction. Julie ended this discussion by asking Doug to think of specific things that she could look for the next time she visited his class. Julie's persistence changed the pattern of collaboration for the remainder of the year as productive collegiality was finally underway. From this point on a new protocol for focused peer observation and feedback was in place.

Manoucheheri, at the conclusion of this report, offers some reflective statements in review of this case study. Although each teacher had a need to improve their teaching, only one of the four teachers recognized this need and pursued answers. The other three teachers entered the collegial team process without having specific goals for personal practice or a vision of how the peer could help improve their teaching. Teaching was perceived by both Ben and Gary as an individual practice whose direction and content was determined by the personal preferences of each teacher. Neither of these men made any attempt to contribute to their peer's professional development. For them, physical proximity did not yield intellectual collaboration.

For the other pair, Julie's persistence caused the teaming activities with Doug to be productive. This resulted in substantial changes in their classroom practice. Julie believed the collaborative process was an essential part of her learning and her 
perceptions of teaching defied isolation in both thinking and process. Manouchehri concludes, that to initiate and sustain a culture in which teachers work with peers to improve both self and peer's practice, the teachers need to first believe that they have the right, and the potential, to influence the profession. This requires them to adopt a new paradigm on the very nature of the profession and how the roles and responsibilities of colleagues are defined.

Having presented some of the skills and attitudes necessary for effective collaboration between teachers, the researcher will now examine some practical guidelines for collaboration. Collaboration can and should occur among all members of the school community, including parents, students, administrators, and teachers, however the emphasis here will be collaboration among the teachers. Meaningful collaboration can arise whenever teachers have genuine interests or purposes held in common (Hawley \& Rollie, 2002). Donaldson (1996) envisions that collaboration can be effectively practiced between pairs of teachers, in informal groups of teachers facing a shared challenge, in formal groups of teachers assigned a specific task, or even among the whole staff. Various strategies are proposed for working in collaborative groups. Donaldson and Sanderson (1996) propose the following four phase model for collaboration:

1. Convening - establishing purpose and membership

2. Contracting-creating the mission of the group

3. Composing- designing collaborative action

4. Following through - taking action and attaining closure 
Eleanor Perry (1997) suggests the following three step “STP” model for guiding the actions of teachers working collaboratively:

1. Agree on the Situation - Where are we now?

2. Choose on Target - Where do we want to be?

3. Create a Path - How do we get there?

Perry further explains this model by providing a practical sequence for problem solving. Teachers must determine the current situation and desired target, and then brainstorm ways to reach the target. Before forging ahead with a solution it is crucial to identify what forces will help or hinder your progress. An action plan can then be developed and implemented. The collaborative process for problem solving is not complete until teachers have evaluated their efforts and made adjustments as needed (Perry, 1997).

In models such as these, or in any collaborative model, it should be impossible for any person's work to go unnoticed. Fullan (2001) calls this occurrence "lateral accountability”. There is, in fact, a great deal of peer pressure along with peer support in collaborative organizations. If teachers are not contributing to solutions, their inaction is likely to stand out. Furthermore, good work is easily recognized and celebrated. Peer pressure can be a powerful motivator for achieving the collaborative group’s objectives.

Perhaps Johnson and Johnson (1999) provide the best summary when describing the process of collaborative work. It is suggested that within collegial groups, teachers should collectively determine what they will learn, how they will learn, and what they will implement. They should supervise the process and respond appropriately to the problems or successes they encounter. Teachers should be able to help one another over individual hurdles because their collegiality provides the professional assistance that each 
teacher requires to succeed. As teachers work through the process of collaboration they become a community of learners and in this community, professional development is guaranteed to occur.

\section{Mentoring: A Transition to Collaboration}

Xenia Christian High School, the site of this researcher's project, like many other schools, currently have a mentoring program in place for new teachers and for teachers with special needs. Mentoring consists of a relationship formed between two unequal individuals, with one individual seeking knowledge and expertise from the other. Collaboration, in contrast, is defined as the equal sharing of information between individuals (Friend \& Cook, 2003) in relationships that provide mutual support and learning. In spite of these distinctions, a mentoring relationship can grow to be collaborative in nature. Therefore, a school that is able to develop a stronger and more sustained mentoring program may be prepared to move naturally toward collaboration as the next step in professional development.

Tom Ganser, a professor at the University of Wisconsin, Whitewater, is a leading expert among educators in mentoring. He describes mentoring, in his article entitled, “Under Their Wing: Promises and Pitfalls of Mentoring” as a productive professional activity that supports new teachers, that provides experienced teachers with a unique way to contribute to their profession, that fosters a close working relationship among teachers and other school professionals as members of a learning community, and that ultimately results in enhanced teaching and improved learning (Ganser, 1999). 
Furthermore, Ganser (1999) reports that the frequency of mentoring programs are likely to expand during the next decade due to a convergence of three trends that will result in a large influx of new teachers: an increasing number of children entering American schools, a growing proportion of teachers who will be retiring, and continuing efforts to reduce class size. Early studies suggest that not only do good induction programs (including mentoring) improve teacher retention, but they influence teaching practices, increase teacher satisfaction, and promote strong professional development and collegial relationships (Curran \& Goldrick, 2002). Checkly (1999) adds that it is often the teachers who lack the support of seasoned, successful colleagues who ultimately leave the profession.

Ganser (2002) in his article entitled "Sharing a Cup of Coffee is only the Beginning” describes a good mentoring program. Good mentoring programs put more effort into supporting high-quality mentoring activities than into finding the perfect match between mentor and new teacher. Although some degree of compatibility is important, it is more important to make sure that mentors and mentees are supported with resources and the time to work together meaningfully. Furthermore, good mentoring programs collect, analyze, and present for consideration information essential to evaluating their effectiveness. Ganzer stresses that it is essential to scrutinize the mentors' effectiveness in carrying out their roles and responsibilities. Mentoring may be the prime vehicle for veteran teachers to pass on the torch of their experiences - and wisdom - to the next generation of teachers.

Howard Hendricks, a distinguished professor and lecturer at Dallas Theological Seminary and also chairman of the Center for Christian Leadership has co-authored a 
book with his son, William Hendricks, entitled, As Iron Sharpens Iron. These authors claim that mentors are able to shape the character and nurture the very soul of an individual (Hendricks \& Hendricks, 1995). This premise is based on Proverbs 27:17 that states, “As iron sharpens iron, so one man sharpens another”. This text, which uses biblical support for mentoring relationships, is written to one desiring to be mentored and to one who wishes to become a mentor. The authors provide the following five reasons for having a mentor: a mentor promotes genuine growth, a mentor is a model to follow, a mentor helps you efficiently reach your goals, a mentor plays a key role in God's pattern for your growth, and a mentor benefits other people/relationships in your life (Hendricks \& Hendricks, 1995). These are powerful reasons why new teachers and even those teachers seeking continued professional and personal growth should seek mentoring relationships.

The second half of this book is written to those wishing to become mentors. Here the authors provide the following five reasons for becoming a mentor: mentoring provides a close relationship with another person, mentoring provides personal renewal, mentoring provides a sense of self-fulfillment, mentoring provides an enhanced self esteem, and mentoring provides an opportunity for your life to impact someone else (Hendricks \& Hendricks, 1995). Certainly veteran teachers and more mature educators also benefit from a mentoring relationship. If fact this is the reason mentoring relationships can often develop into collaborative relationships. What begins as one-way learning naturally can lead to learning that is of mutual benefit for both individuals.

Ganser (1999) also recognizes the personal value of being a mentor. Veteran teachers frequently characterize working closely with beginning teachers as a source of 
fresh ideas about curriculum and instruction that are immediately useful to them. Like cooperating teachers, mentor teachers emphasize that working with a beginning teacher requires continual self-analysis of their own work, as they are asked to make explicit what has become automatic over the years in terms of procedural matters, curricular matters, instructional matters, and classroom management matters.

Leslie Huling, in her article entitled “Teacher mentoring as Professional Development" provides three specific benefits of being a mentor. First, professional competency - as mentor teachers assist their protégées in improving their teaching, they also improve their own professional competency. Mentor teachers frequently characterize their working closely with beginning teachers as a source of new ideas about curriculum and teaching (Ganser’s study, 1997 as cited by Huling \& Resta, 2001). Second, reflective practice - mentoring forces mentors to be reflective about their own beliefs about teaching, students, learning, and teaching as a career (Huling \& Resta, 2001). Third, renewal - a number of researchers have reported that mentors experience professional renewal, are re-energized, and often strengthen their commitment to the teaching profession (Ford and Parson’s study, 2000 as cited by Huling \& Resta, 2001). Ganser (1999) sums up the natural transition from mentoring to collaboration when he shares that mentoring gives beginning teachers special access to veteran teachers' craft knowledge, expertise, and wisdom, while simultaneously enriching the careers of those veterans. Huling (2001) adds that the benefits of mentoring programs are substantial for both novice and mentor teachers. School leaders need to understand that creating a structure that allows experienced teachers to work with novice teachers will ultimately benefit the students of both novices and mentors. Additionally, because 
mentors can exert substantially greater influence on the school organization than novices, the benefits of professional development that mentors derive from mentoring may be of equal or even greater importance than those experienced by novice teachers. Principals must recognize the potential benefits for providing the structure and the time for a quality mentoring program in their school. Furthermore, evidence suggests that a well developed mentoring program may provide the roots necessary for supporting the spread of collaboration throughout other facets of the school community.

One creative method that teachers may find useful for mentoring is e-mail. Zach Kelehear has written a fascinating article entitled, “Tell Me What Went Well with Your Lesson, Sam”. Kelehear (2002), cites several schools that have instituted what is called “empathic e-mailing” into their mentoring programs. Empathic e-mailing is one way of bringing new teachers together with their mentors without changing established schedules. Mentor teachers and new teachers often have difficulty finding time to talk and listen to each other and this challenge can diminish an effective mentoring program. Empathic e-mails can be an effective medium for teacher reflection. The act of pausing to write about events of the day can be an important habit for successful teaching. Reflection moves from being a solitary undertaking, as in some journal writing, to a collaborative one where teachers engage each other via email. And because e-mail is convenient and immediate, teachers often reflect more frequently (Kelehear, 2002).

\section{$\underline{\text { A Case Study }}$}


This case study describes a collaborative mentoring relationship between the coauthors, Frances Kochan and Susan Trimble. Their relationship provided opportunities for them to develop dispositions and abilities that have been invaluable in strengthening their capacities to grow personally and professionally (Kochan and Trimble, 2000). This article recounts their journey that began in 1992 and covers career changes and personal growth through new careers in education. When the article was written these individuals served as university professors in different institutions but still remained in contact by email and phone.

In 1992 Susan was a middle school science teacher and graduate student who was looking for a mentor. In preparation for this relationship, Susan engaged in selfassessment of her strengths and weaknesses, formulated her goals, and searched for potential mentors. Susan chose to ask Fran, a principal and director of a university laboratory school, to be her mentor. Fran had never been involved in either side of a mentoring relationship, but was impressed by two factors presented by Susan. Fran recounts, "She told me what she had done in the way of self-analysis and what her goals were. Second, she expressed concern about the time demands on me and spoke of alternate ways we might connect...I realized that she would be proactive and would assume responsibility for the mentorship and her own learning. This helped establish a level of trust”.

During the initial meetings, Susan and Fran worked to lay the groundwork by establishing norms, assuring confidentiality, keeping conversations on professional issues, maintaining time limits, and balancing the talk between the two of them. Fran recalled that Susan worked diligently to assure that our meetings were well planned, 
specific, and did not take too much time. "Her preparation”, Fran stated, "enabled me to develop confidence in her. This in turn made me willing to trust her with my stories, experiences, weaknesses, and concerns”. This preparation, accomplished during several months of bi-weekly meetings, allowed the mentoring relationship to grow into a more intense level of sharing and working.

The co-authors shared several specific actions that describe this "working” phase of their relationship. They began to talk more openly about issues important to each of them, they learned to engage in discussions not by giving answers to one another but by forming guiding questions, and they worked on specific problems and openly discussed concerns, mistakes, and fears. These meeting were characterized by a time of taking risks, engaging in self-analysis, trying out new behaviors, and seeking and receiving feedback on the results. Perhaps the most interesting phenomenon that occurred in their relationship was the blurring of the mentor and mentee roles and a transition to a comentoring relationship. Fran recalls "like Susan, I was finding myself reflecting on past conversations and learning from them...these were wonderful opportunities for me to deal with my own values, beliefs, and actions...I found myself more able to discuss successes and failures and learn from them as I shared”.

Mentoring relationships can be filled with frustrations and unexpected surprises as Susan shared in the following illustration. During a time period, Fran's schedule was constantly shifting and interfering with their scheduled mentoring time. Initially, Susan found this to be extremely frustrating, until Fran began inviting her to stay and see how she, as a school principal dealt, with these unexpected interruptions. Through these observations Susan states, "I was shocked by the myriad tasks that had to be handled (by 
Fran). I began to grasp 'the big picture' of the work of a school administrator”. These shared experiences became powerful tools for learning.

The co-authors made several observations as they commented on their dynamic relationship. Their relationship helped them to become more reflective; make better judgments; and initiate and engage in collaborative activities using enhanced communication skills. Additionally they have been encouraged to take risks, tolerate ambiguity, and seek critical feedback to improve their personal and professional capabilities. These co-authors concluded that both emerging and established professionals can benefit from proactively engaging in mentoring/co-mentoring relationships. Furthermore, mentoring and co-mentoring relationships that are open and trusting can enhance the development of personal and professional collaborative work skills.

\section{Collaboration: A Means to Professional Development and School Reform}

Current trends in education point toward an increasing emphasis on collaboration as a means of professional development for teachers and collaboration may even have the potential for reforming the embedded culture of isolation. Teacher learning lies at the heart of improving education in our society, for it is teachers that have the ability to directly influence the learning for children (Sykes, 1996). Principals and other school leaders must recognize that teachers, as internal resources, are a cost effective yet valuable means for school improvement (Johnson \& Johnson, 1999). Several researchers 
believe that collaboration in schools is a fundamental element of teacher research, professional development, and school reform.

Learning in the setting where teachers work, or learning in context as Fullan (2001) suggests, is the learning with the greatest payoff because it is more specific. Learning in context provides the means for developing teachers as leaders. Teachers, more than educational experts from outside the school or even their principals, understand the technical skills that are most important in their classroom. As teachers are given opportunities to collaborate with their colleagues, certainly the necessary skills can be learned and developed in a manner best suited for the school, and likely for the classroom itself (Koehler \& Baxter, 1997). This local professional development strategy of collaboration among teachers is sure to benefit teachers in their daily practice of teaching.

Not only is classroom teaching improved, but collaboration among teachers has the potential for school-wide reform. Shared contributions among those who engage in collaborative inquiry are an important and necessary component of a collegial learning community. Innovations and questions generated from teachers working together can provide springboards for instigating school-wide inquiry aimed at altering the broader situation itself (Emihovich \& Battaglia, 2000). At the very least, research indicates that most teachers want to learn from and interact with other teachers. Bush (2003) cited a study that included approximately 27,000 participants. The data showed that threequarters of the sample (at all levels of schooling) would like to observe other teachers at work. They did not feel that they knew their fellow teachers, how they behaved with students, their educational beliefs, or their competence. Overall, teachers in this study 
felt they had control over decisions concerning the students in their classrooms, but a lack of control over decisions concerning themselves.

Colvin (1996) claims that teachers demand opportunities to observe their colleagues teaching for understanding, to try it out themselves, and then to think and talk about their experiences within the supportive learning community that holds the promise for school-wide reform. Given this opportunity, teachers working together collaboratively will be able to reduce the constraints of autonomy and initiate steps of reform. Professional development of this character, within a community of learners, promotes the notion that teachers are responsible not only for their own professional development but also for their school's improvement (Bush, 2003). 


\section{Chapter III: The Project}

The researcher has developed a project that is designed to provide regular opportunities for collaboration among teachers. Meaningful collaboration, according to research, should enable teachers to do their jobs better; the heart of professional development. Increased student achievement is the expected outcome of any effective professional development program. However, measurable changes in student achievement can take years to identify. Therefore, this study will attempt to measure changes in teacher perceptions of adequacy in dealing with classroom situations and improvements in accomplishing teacher responsibilities.

\section{Project Background}

Graduate studies, beginning in 2001, provided the researcher with frequent opportunities for self-evaluation as a teacher. This has led to not just personal analysis of teaching practices, but also to an analysis of school-wide practices. God has placed within the researcher a desire to improve the education and experiences offered to students at Xenia Christian High School. This desire led to actions as the researcher initiated a school improvement project in the 2002-2003 school year.

That project was designed to shift administrative responsibilities of teacher extraduties from the administration to the teachers. In the past, the administration rotated teachers through several different extra duties throughout the year. Since the project's implementation, teachers have been working together in teams (collaborating) to create expectations and schedules for accomplishing their assigned duty. Each teacher is 
accountable to the other members of their group for performing the extra duty properly. Some benefits of this program have been more flexible scheduling to meet each teacher's individual needs, decreased teacher absences from a duty, and greater consistency in carrying out the expectations of the duty. This program, based on the collaborative work of teacher-leaders, is now in its second year of implementation and has proven beneficial for the teachers, administrators, and students.

Furthermore, during the spring of 2003, the administration of Xenia Christian High School provided its teachers with approximately three hours of time to work together in teams to evaluate and propose solutions to four school-wide issues. The time for the groups to meet was taken from the traditional faculty, morning devotional time. Approximately six teachers participated in each group that met over a period of two weeks. The issues discussed included the following: evaluation of and ideas for the weekly chapel, evaluation and proposals concerning the faculty's perspective of the eligibility process (primarily athletics), evaluation and proposals concerning devotional/homeroom classes, and a proposal for a new Scantron ${ }^{\circledR}$ machine. This opportunity for shaping some school-wide issues was appreciated by many of the teachers and provided valuable information to the administration.

It is the goal of the researcher that collaborative opportunities such as these will be sustained and that the most recent research project, as detailed below, will influence even more deeply the effectiveness of teachers in their classrooms.

Perhaps the most powerful experience that has led the researcher to continue pursuing school improvement through collaborative experiences has been the structural design and location of the researcher's classroom. A common storage area and a short 
hallway connect the researcher's classroom with another science teacher's classroom. During the past three years the researcher has personally benefited from collegial interaction afforded by the frequent opportunities to interact with this colleague. This classroom arrangement has provided countless opportunities for informal observation and interaction. It is wonderful to be welcome in a colleague's classroom while he is teaching, and it is also fantastic to feel no anxiety when this colleague observes the researcher teaching. This exposure, beyond creating an increased level of collegiality, has actually resulted in the formation of a unique culture in each of the classrooms. Not only have these teachers, as a professional teaching pair, benefited from this arrangement; but it is believed that the students have benefited as well.

It is the belief of the researcher that a sovereign God has creatively and powerfully orchestrated these recent collaborative experiences for a distinct purpose. It is an honor to be called by God to fulfill a small part of His mission at Xenia Christian High School. The researcher honestly can say that this current project is an extension from the heart that God is shaping within him.

The primary objective of this current project, entitled the Buddy System, was to encourage teachers to observe their peers teaching in the classroom and then to have an opportunity to discuss their observations collaboratively. The name "Buddy System" was adopted from a book written by Gail Bush (2003) entitled The School Buddy System. This comprehensive text provides a thorough discussion of the historical context and the current trends in collaboration.

During the summer of 2003 the researcher began to formulate his plans for the creation of the Buddy System. Beyond the countless hours spent in research, the 
researcher also had opportunities to gather information and discuss the project with several members of the school family. This included a one-hour meeting with the Superintendent of Dayton Christian Schools, Inc., several meetings and conversations with the principals of Xenia Christian High School, and discussions with several colleagues from the school teaching staff. These opportunities to interact with education professionals provided the researcher with courage and affirmation.

Furthermore, these interactions helped to guide and shape the structure of the Buddy System. For instance, the superintendent wisely cautioned the researcher to be realistic in one important perspective, the existing isolationism within schools. Research claims that many schools in America are marked deeply by isolation, but the researcher did not really understand where Xenia Christian High School stood in relation to other schools. The researcher was assured by the superintendent that the culture of Xenia Christian was far from being deeply marked by isolation. This information helped the researcher to understand that this project should not be designed to break down walls of isolation, but to open wider the doors of interaction that already exist.

Another valuable opportunity arose from conversations with the principal of Xenia Christian. As the Buddy System project began to take shape, the principal suggested that the project be implemented by all the teachers and not by just a few interested participants. This transitioned the scope of the project from the level of an experiment to a full-fledged school improvement project. This opportunity to influence all the teachers was certainly daunting, but in the end it provided more data and offered greater potential for school improvement through widespread professional development. 


\section{The Setting}

Xenia Christian High School, a campus of Dayton Christian Schools, Inc., is located in southwestern Ohio. Approximately three-hundred $7^{\text {th }}$ to $12^{\text {th }}$ grade students, most from rural or small suburban communities, and nearly twenty-five teachers make up the primarily white school family. Xenia Christian is driven by biblical principles and has a vision to support Christian families and the local church in the education of students in a profoundly Christian environment.

\section{The Buddy System}

The Buddy System was designed by the researcher to investigate the professional development caused by offering peer observation and supporting collaborative opportunities for the teachers. This project was introduced to the high school teachers during two thirty-minute sessions scheduled by the principal during the faculty orientation meetings held in August of 2003, just prior to the beginning of the school year. Twenty-one full-time teachers, including the researcher; two administrators, who also teach part-time; and the full-time principal were asked to participate in this project. Teaching experience among the participants ranged from including new teachers to those with more than thirty years of teaching experience. The project was implemented for one semester, sixteen weeks, before being analyzed by the researcher.

During the first faculty orientation session the researcher asked the faculty to complete a survey designed to measure the effectiveness of the current means of professional development offered to Xenia Christian High School teachers and to measure their interest in peer observation and collaboration. See Appendix A for a copy 
of this survey. The results of this survey revealed some interesting patterns among the faculty of Xenia Christian High School. The following is a brief discussion of the results of the survey that was administered prior to the introduction of the Buddy System. See Appendix B for a complete summary of the survey results.

A major contributor to professional development is experience. The survey revealed that one-hundred percent of the teachers consider teaching experiences to provide more in making them a better teacher than do workshops and traditional inservice programs offered by Dayton Christian Schools, Inc. and the Association of Christian Schools International. Furthermore, the survey asked teachers to identify the particular source of experience that has had the greatest influence in making them a better teacher. The sources of experience offered by the researcher included interactions with students, other teachers, and the principal or other administrators. Eighty-one percent of the teachers ranked their experience due to interactions with other teachers as either their highest or tied with their highest based on perceptions of professional development. Seventy-one percent selected students as their highest or tied with their highest. On the other end of the spectrum, only fourteen percent of the teachers selected the principal or other administrators as their highest or tied with their highest. This finding reveals that teachers at Xenia Christian High School depend much more heavily on interactions with other teachers and students, than on interactions with the principal, as a source of professional development.

The survey also asked teachers to reveal their sources for answers when dealing with problems in their classrooms. Out of the list of five options, seventy-four percent of the teachers surveyed ranked "another teacher” as either their first and second choice. 
This survey also confirmed that teacher satisfaction is derived primarily through internal motivations. One hundred percent of the teachers ranked student achievement and personal success ahead of the two external sources of satisfaction offered in the survey.

The principal of Xenia Christian High School perceived that teacher observations and evaluations, for which he was responsible, provide very little in helping the staff be better teachers. This perception was confirmed by the survey. Of a list of seven items, seventy-four percent of the teachers ranked principal evaluations as the lowest or secondlowest factor in helping them be a better teacher.

The results of this survey were consistent with the major themes found in research. Furthermore, the results confirmed many of the researcher's perceptions of the Xenia Christian High School staff. In summary, the following conclusions can be drawn: 1. Teachers at Xenia Christian High School are most satisfied from internal motivations. 2. Teachers at Xenia Christian High School most often go to other teachers for answers when dealing with problems.

3. Teachers at Xenia Christian High School do not consider principal evaluations as an effective means to being a better teacher.

4. Teachers at Xenia Christian High School view experience as a valuable source of professional development.

During the second session of teacher orientation in August of 2003, the researcher introduced to the teachers of Xenia Christian High School the Buddy System. See Appendix C for a copy of the handout provided to the teachers. Besides the handout, 
each teacher also received a full sized spiral notebook that was to be used as a journal. The notebook also contained the following items:

1. "GREAT” - Good Reports Edify And Testify. This reminder, to follow the Matthew 18 principle when dealing with conflict, was glued to the cover of the notebook. See Appendix C

2. Four Buddy Watch forms. See Appendix D.

3. Two Buddy System Progress Reports. See Appendix E.

4. Approximately twenty-five small cards containing various quotes from Noah BenShea's book entitled, Great Quotes to Inspire Great Teachers or encouraging Bible verses. See Appendix F for a sampling. The researcher hoped that these encouraging words would help fuel discussions among the teachers.

The Buddy System was presented with having two primary activities, Buddy Buoy and Buddy Watch. The Buddy Buoy was designed to provide time for teachers to meet with their assigned partner (Buddy) each Wednesday morning from approximately 7:307:50 P.M. Traditionally this time has been used for teacher-pairs to pray together as "Prayer Partners". The principal, as usual, selected the common-gendered teacher-pairs, but during the extent of this project they were called "Buddies”. The researcher also advised the principal to not pair up teachers who had a common planning period. This was necessary for the success of the Buddy Watch.

The purpose of the Buddy Buoy time was for teachers to encourage and pray for one another. The intent was that partners would be available to help one another stay afloat. The researcher encouraged the teachers to use a significant amount of this Buoy Time to discuss and pray for issues pertaining to their classroom teaching. Furthermore, 
during the orientation session, the researcher asked the teachers to keep a prayer journal and other reflective notes, to be accountable to one another for a certain teaching responsibilities, and to plan, review, and document the Buddy Watch observations. In conclusion, the Buoy Time was designed to provide teachers the opportunity to reflect on and discuss classroom issues collaboratively.

The second activity within the Buddy System was called the Buddy Watch. Each teacher was asked to observe their Buddy teach a class four times during the first semester. These observations where made during the observing teacher's planning period. The purpose was that observing-teacher would to gather information that could be used to increase his or her effectiveness as a teacher. During the orientation session it was stressed that the observation was not to be considered a form of teacher evaluation. In fact, the researcher intended that the observing-teacher enter the Buddy's classroom with the attitude that there will be something observed that needs to be learned. In the past when an adult came into the classrooms of Xenia Christian High School, it was typically the principal evaluating the teacher. By having the same Buddy for at least one semester, the researcher hoped that teachers would begin to feel more comfortable and less threatened while being observed by someone who was there to learn and not evaluate.

Teachers were instructed to observe their Buddy only when invited and to document their observations on the Buddy Watch Form. The researcher also encouraged the observing-teachers to be creative and to try in their own classrooms something new that they had observed. It was hoped that the Buddy Buoy time and the Buddy Watch opportunities would perpetuate collaboration and provide teachers with new ideas and the 
support they needed to try those ideas effectively in their own classrooms. If such progress could be made, then professional development in a very personal and practical means would be achieved.

A secondary outcome of the Buddy System was to provide the principal with another resource when doing teacher evaluations by incorporating teacher selfevaluations into the process. Each teacher was asked to work with their Buddy in completing the Buddy System Progress Report. This exercise was designed to encourage personal reflection and provide another collaborative opportunity. During the final orientation session, teachers were asked to complete - early in the semester - the portions of the progress report that were relevant to them; discuss throughout the semester the ideas with their buddy; and then provide a copy of the completed form for the principal near the end of the semester. This document would then be used as another tool in the process of evaluating the teacher. The principal anticipated that these progress reports might provide another perspective, the teacher’s self-analysis, of classroom life.

The Buddy System, if effective, would get teachers thinking about their teaching, talking with others about their teaching, and creating new and valuable ideas about teaching as they collaborated with one another.

\section{Project Results}

The researcher, during the second orientation session, encouraged the teachers to record new experiences and reflections in their journals and to document progress on the forms provided. It was also firmly stressed that everything in the journal including each document belonged solely to each teacher and that any information shared with the 
researcher would be voluntary. The only exception to this was the Buddy System Progress Report that was to be completed and shared with the principal. This arrangement was designed to give each teacher the freedom and security to reflect on their teaching and to try new ideas without the fear of anticipated evaluation. Several times during the semester teachers were reminded by the researcher to complete their observations. Near the end of the semester the teachers were asked to photocopy any information that they would be willing to share with the researcher. Many teachers shared copies of their actual documents while others just shared their perceptions of the project.

Besides collecting information shared voluntarily from the participants, the researcher during the final week of the first semester chose to evaluate the effectiveness of the Buddy System with a brief survey. See Appendix G. Out of appreciation for each teacher's eager participation and patience throughout the scope of this project, the researcher attached a small chocolate treat to each survey. The researcher realized the importance of each participating teacher and recognized that the following results could not have been obtained without their wonderful cooperation.

The results of the survey taken at the conclusion of this project indicate that most of the teachers appreciated the opportunities for observation (Buddy Watch) and collaboration (Buddy Buoy). Of the eighteen post-project surveys completed, ninety-four percent of the teachers indicated as either their first and second choice, from a list of five choices, a preference for keeping the project next semester or expanding it to include observations of other teachers. Additionally, for the Buddy System's overall evaluation a Likert scale was incorporated. The effectiveness of the project was rated with the value 
of "one" corresponding to the project "has helped me to be a better teacher" and the value of "five" corresponding to "the project has not helped me to be a better teacher". Only one of the eighteen responding teachers rated the overall project negatively with a score of four, while the average score from all the participating teachers was two. The survey also revealed that each teacher accomplished, on average, just over 2.3 observations. See Appendix $\mathrm{H}$ for a complete summary of the post-survey results.

Several teachers also provided some final comments concerning the project. One teacher responded, “The idea is a good one. I enjoy meeting with my Buddy - she’s a great teacher - and using that time as prayer time.” Another added, "Great idea - easy to do. Love being "free" to observe others - I do learn that way!" Comments such as these provide evidence that the Buddy System contributed to teacher interaction and teacher learning. This observation was supported by the following comment from another teacher, "I truly benefited from this. I wish that I had spent more time in her classroom this semester. I would love to have an excuse to be in many teachers' classrooms. I'm curious about the big picture that students get when they go from room to room”.

Another teacher added, "It is good to have openness and sharing. This school has a professional, non-competitive attitude among the teachers. Everyone wants to help everyone do his best. Perhaps a more open climate has been created”. It is interesting to note that this teacher in her final assessment described accurately a culture of collegiality as becoming more prominent at Xenia Christian High School due to the implementation of the Buddy System. Another teacher recognized the "big picture" by commenting that this project was a "big improvement over previous evaluation and development methods". 
The researcher also collected responses that were critical of the project or that provided suggestions. One teacher revealed, "It has been helpful, but I think I would be doing the same things without the system, without the paperwork". Several other teachers commented that they felt they would have benefited more from observing and interacting with teachers of a similar content area. For instance one teacher commented, "I feel personally that I would've benefited more by going to observe someone of my choice (more related to my area)". Two other expressed their concern about the issue of time. "I really use/need my planning period, I hate giving it up even 4 times a semester" was the response of one such teacher. The other teacher was concerned that the group meetings at 7:30 on Wednesday mornings often lasted more than a few minutes. This, he commented cut into "the time with our buddy". The researcher added from personal experience that of the first ten Wednesday meetings with his Buddy, three were cancelled due to special meetings called by the principal.

Results such as these listed above comment on teacher perceptions of the Buddy System. However, the effectiveness of professional development is best measured by actual changes in the classroom. Based on this observation, the researcher would like to present some of the information that teachers volunteered from their Buddy Watch forms and for their Buddy System Progress Reports.

Each teacher who shared information from their Buddy Watch forms included information describing things they liked about the teacher they were observing. One observer described her buddy as being "very well organized, patient and conscientious in her teaching of her students. She deserves to pass on a love of reading to her students”. Another added, "She had many students on many different projects. She seemed eager to 
help them”. The following descriptions of a teachers actions were also recorded, “Clear/detailed directions...Teaches to all learning modalities: verbal, visual, demonstrates, involves students in directions, asks thinking questions, students are attentive, and feel free to ask questions”. Apparently, teachers who were observing had little difficulty in identifying positive attitudes and behavior as their Buddies taught.

Besides including general observations, just over one-half of the Buddy Watch forms contained ideas that teachers might wish to try in their own classrooms. Several teachers shared that they wished to use technology and internet resources more in their classrooms. Others observed ideas for classroom management. For instance, one teacher liked the idea of having students “use a visible sign for when they're finished with a task". Another wished to be, "more efficient...a little more thought to being "fair" and balanced in group work/seating chart/etc".

Teachers also recorded thoughts concerning new methods of reviewing material with students. Several teachers shared their desire to try new ideas for classroom decorations and devotions that are designed to reinforce the lessons being studied. Finally, one teacher observed their Buddy giving students time to record their thoughts during class, and wished to adopt that idea in their own classroom. It was certainly evident from the Buddy Watch forms that observing-teachers gained practical ideas for use in their own classrooms. But an examination of the Buddy System Progress Reports would reveal just how many new ideas and professional improvements were put into practice during the first semester.

Nearly two-thirds of the teachers who turned in their progress reports to the principal were also willing to share them with the researcher. One-hundred percent of 
those teachers listed new ideas that they had tried or areas of responsibility that they improved on during the semester. One teacher effectively implemented technology into more of his classroom lessons. Another tried new ways of incorporating cooperative learning. One teacher tried a new review game that he had observed and the "kids loved it". The "Crazy Review" turned into what he called the "Bullwinkle Review", and it was surprisingly successful. Another teacher used an idea that he had observed of having kids "give good and bad examples of how to fulfill the requirement" and his results were "funny and successful".

Nearly every progress report included professional responsibilities which the teachers improved on during the first semester. Teachers felt they had improved in areas such as classroom discipline, communicating with parents, completing necessary paperwork on time, taking attendance, and in being prepared when class begins. Several cited the fact that being held accountable by their Buddy helped them to make improvements in completing responsibilities as professionals.

Due to the fantastic cooperation from the administrators and teachers at Xenia Christian High School, the researcher received an abundance of quality information concerning the results of the Buddy System. In fact, in the preceding portion of this document it has been difficult to reduce those results into a manageable size. In the concluding chapter of this document, the researcher will attempt to draw some final conclusions from this project and will also propose some recommendations for future study. 


\section{Chapter IV: Conclusions and Recommendations}

\section{Conclusions}

Many interesting conclusions can be drawn from the Buddy System project, but the researcher would like to identify and develop just four of them.

First, the teachers at Xenia Christian High School expressed an overwhelming desire to continue or even expand the scope of teacher observations. This is likely based on the assumption that these teachers consider themselves to be learners. They expressed appreciation for the project because it offered them real answers to the myriad of problems they face every day. Through the observation process, countless new and practical ideas were recognized; and even more encouraging, many were tried. Several teachers cited examples of these new ideas being implemented with great success. These teachers realized that the Buddy System provided them with an effective form of professional development.

Second, one-hundred percent of the teachers at Xenia Christian High School, who shared Buddy Watch forms with the researcher, identified specific ideas that they learned from their Buddy. This fact was realized even though some new teachers and veteran teachers were paired together for the duration of this project. What many would consider to be an excellent opportunity for one-way mentoring turned into the sharing of ideas in a collaborative manner. This result is consistent with research that claims that mentoring, when nurtured along, can prove to be mutually beneficial for both participants.

Third, professional development, which must begin with teachers in their classrooms, should also influence their professional relationships with others in the school community. The Buddy System, and particularly the Buddy Buoy time, provided 
many teachers the opportunity to seek accountability from their Buddy in accomplishing expected responsibilities in a more professional manner. There was good growth reported in accomplishing work required by the administration. Other teachers mentioned progress in communicating better with students and parents. Some of this change must be attributed to the opportunity that teachers had to interact with each other. To be held accountable meant that teachers had to examine themselves to identify deficiencies and then be willing to share there deficiencies with their Buddies. Relationships between teachers at Xenia Christian High School must have already been marked by trust and openness for accountability to have produced such significant improvements in teacher-responsibilities in such a short period of time.

Fourth, the researcher believes that this project has produced a fundamental change in an important teacher perception. Traditionally, classroom observations are tied closely with evaluation. Typically, when an adult entered a classroom the intent was to scrutinize the teacher. It was refreshing, as a teacher who was observed during this project, to feel the fear associated with evaluation begin to diminish with each subsequent observation. Time and again, observing-teachers wrote encouraging comments concerning their Buddy. When reviewing these documents, the researcher did not find one comment of criticism or even hinting at evaluation. In fact, it would be impossible for a teacher to not be encouraged by the comments recorded by their Buddy. In this sense, observations moved from being a negative experience to being a very positive one. Moreover, the discussions between partners that followed the observations certainly provided buoyancy, a lifting of the spirits, to stay afloat in the deep water of teaching. 
These conclusions reveal that peer observation, personal reflection, collaborative interaction, and kind words can lead to effective professional development. The entire success of the Buddy System relied on the manipulation of internal resources already existing at Xenia Christian High School, primarily the teachers themselves. Great progress in professional development was made in spite of the fact that no outside experts or resources were necessary. Perhaps, as the research indicates, teachers themselves hold the most powerful keys to better schools and increased student achievement by unlocking their own potential for professional development.

\section{$\underline{\text { Recommendations }}$}

There are a multitude of possibilities for professional development through collaborative experiences at Xenia Christian High School as well as at every school. When evaluating any collaborative project, such as the Buddy System, obvious weaknesses surface and further work must be done. The researcher would like to identify four specific areas that require further attention.

First, an interesting phenomenon surfaced in the surveys given at the conclusion of the project. There seemed to be a disconnection between the value of observations and the value of reflecting on those observations with a Buddy. Teachers expressed their interest in further observations, and many suggested that opportunities to observe other teachers would be even more beneficial. However, teachers shared their desire to keep their same Buddy for the Buddy Buoy portion of the project, yet they still wanted an opportunity to observe other teachers. Moreover, no provision was made for reflection and sharing with these other teachers. Research, as cited in Chapter II, claims that 
valuable progress can be made when teachers reflect and share ideas with one another. Apparently, the Buddy System was not effective in providing the participating teachers overwhelming-successful experiences as they discussed the results of the observations. It appears that the teachers were content with the success of the observations, but may be missing an important piece of the collaborative process.

Second, it is recommended that further work be done in developing peer observation practices into peer coaching. Peer Coaching for Educators, written by Barbara Grotesman (2000) is an excellent resource for educators interested in beginning a peer coaching relationship. Peer coaching, this author claims, can be a valuable tool for the professional development of teachers. It places expectations on the observing teacher and requires reflection and feedback in order to be effective. Obviously, due to the increased responsibility, peer coaching could not be implemented until teachers became comfortable with peer observations. It would be fantastic if some teachers from Xenia Christian High School eventually became interested in peer coaching and could realize some of its powerful results.

Third, further study must be done when considering the formation of peer partners or Buddies. Several teachers indicated a desire to observe and meet with teachers from a similar content area. It would be interesting to evaluate the results of professional development of those in interdisciplinary pairs with those paired with teachers of the same discipline. Additionally, various combinations of "Buddies” based on teaching experience may also yield some valuable results. Perhaps the Buddy System is flexible enough to allow teaches to work effectively in groups of three, called triads, instead of in pairs as this study required. Triads would provide teachers with more variety in their 
observations and still maintain opportunities for reflection and sharing with known and trusted peers.

Fourth, any collaborative effort requires time from each of the participants. Further work must be done in providing teachers with the time necessary to make observations. Also, doing the "paperwork" requires time but is a valuable part of reflection. As indicated in this project, the time set aside on Wednesday mornings for Buddies was often shortened or eliminated altogether. It is difficult for administrators to give time for collaborative projects that do not produce immediate and easily measurable results. However, as this project indicated, with teachers and principals both willing to give up some of their time, exciting professional development can take place.

Time is also necessary to evaluate the effectiveness of collaborative activities. For example, it would have been beneficial at the conclusion of the first semester, to have all the teachers together to brainstorm and share their perspectives of the Buddy System. However, this would have required teachers to set aside time from this already busy time of the school year.

Much more work needs to be done in providing teachers with the time necessary for collaboration. Quite possibly, after teachers begin to realize for themselves the benefits of collaboration, including some time-saving benefits, they will be willing to give up some of their own time. Until then, educational leaders must have the courage to look past the barrier of time and seize the professional development opportunities that collaborative experiences promise to provide. 


\section{APPENDIX A}

Please take a moment to complete the following survey.

HOW HAVE WE DONE?

1. Inservice workshops provided at DCS have helped me to be a better teacher.

$$
\begin{array}{llllllll}
7 & 6 & 5 & 4 & 3 & 2 & 1 & \text { NA }
\end{array}
$$

Strongly agree

Strongly Disagree

Not

Applicable

2. Inservice general sessions provided at DCS have helped me to be a better teacher.

$\begin{array}{llllllll}7 & 6 & 5 & 4 & 3 & 2 & 1 & \text { NA }\end{array}$

3. ACSI workshops have helped me to be a better teacher.
7
$6+5$
54
32
1
NA

4. ACSI general sessions have helped me to be a better teacher.
7
65
4
32
1
NA

5. Experience due to interactions with students has helped me to be a better teacher.
7
65
4
32
1
NA

6. Experience due to interactions with other teachers has helped me to be a better teacher.

$$
\begin{array}{llllllll}
7 & 6 & 5 & 4 & 3 & 2 & 1 & \text { NA }
\end{array}
$$

7. Experience due to interactions with the principal and other administrators has helped me to be a better teacher.
7
5

4.
3
2
NA 


\section{WHERE MIGHT WE GO!}

\section{Five years from now I would like to be}

Rank the following items in order from 1 - most likely to 4 - least likely.

__ out of the teaching profession

__ an administrator a teacher with similar responsibilities a teacher-leader, helping other teachers and shaping school decisions

2. If time and money were not an issue, the following would help me be a better teacher.

Rank the following items in order from 1 - most important to 7 - least important. continued formal education, graduate classes, workshops observing other teachers teach having input in school-wide policies, procedures, and goals appropriate technology and equipment for the classroom smaller class sizes more frequent principal evaluations of my teaching more contact time with the students

3. When dealing with problems in my classroom, I look to what source for answers. Rank the following items in order from 1 - most often to 5 - least often. books and articles principal or administrator another teacher trusted friend who is not in the building (pastor, spouse, etc.) teacher's handbook

\section{Teaching is most satisfying when}

Rank the following items in order from 1 - most satisfying to 4 - least satisfying the principal is happy parents are content students are learning I know what I need to do and can do it 


\section{APPENDIX B}

Survey Results: (Reported as average scores)

\section{HOW HAVE WE DONE?}

1. Inservice workshops provided at DCS have helped me to be a better teacher.

$\begin{array}{ccccccc}7 & 6 & 5 & 4 & 3 & 2 & 1 \\ \text { Strongly agree } & & & & & & \text { Strongly Disagree }\end{array}$

2. Inservice general sessions provided at DCS have helped me to be a better teacher.

$\begin{array}{lllllll}7 & 6 & 5 & 4 & 3 & 2 & 1\end{array}$

3. ACSI workshops have helped me to be a better teacher.

$$
\begin{array}{lllllll}
7 & 6 & 5 & 4 & 3 & 2 & 1
\end{array}
$$

4. ACSI general sessions have helped me to be a better teacher.

$\begin{array}{lllllll}7 & 6 & 5 & 4 & 3 & 2 & 1\end{array}$

5. Experience due to interactions with students has helped me to be a better teacher.

$$
\begin{array}{lllllll}
7 & 6 & 5 & 4 & 3 & 2 & 1
\end{array}
$$

6. Experience due to interactions with other teachers has helped me to be a better teacher.

$$
\begin{array}{lllllll}
7 & 6 & 5 & 4 & 3 & 2 & 1
\end{array}
$$

7. Experience due to interactions with the principal and other administrators has helped me to be a better teacher.

$$
\begin{array}{lllllll}
7 & 6 & 5 & 4 & 3 & 2 & 1
\end{array}
$$

\footnotetext{
$\underline{7.1 \text { yrs. }} \quad$ Teaching experience at DCS
} 


\section{WHERE MIGHT WE GO!}

\section{Five years from now I would like to be}

Rank the following items in order from 1 - most likely to 4 - least likely.

$\underline{3.3}$ out of the teaching profession

$\underline{3.5}$ an administrator

$\underline{1.7}$ a teacher with similar responsibilities

1.4 a teacher-leader, helping other teachers and shaping school decisions

2. If time and money were not an issue, the following would help me be a better teacher.

Rank the following items in order from 1 - most important to 7 - least important.

$\underline{3.7}$ continued formal education, graduate classes, workshops

3.6 observing other teachers teach

$\underline{5.1}$ having input in school-wide policies, procedures, and goals

3.4 appropriate technology and equipment for the classroom

$\underline{2.9}$ smaller class sizes

$\underline{5.8}$ more frequent principal evaluations of my teaching

3.2 more contact time with the students

3. When dealing with problems in my classroom, I look to what source for answers. Rank the following items in order from, 1 - most often to 5 -least often.

$\underline{3.8}$ books and articles

$\underline{2.4}$ principal or administrator

1.7 another teacher

3.1 trusted friend who is not in the building (pastor, spouse, etc.)

$\underline{4.4}$ teacher's handbook

\section{Teaching is most satisfying when}

Rank the following items in order from 1 - most satisfying to 4 - least satisfying

$\underline{3.9}$ the principal is happy

$\underline{3.1}$ parents are content

$\underline{1.5}$ students are learning

1.6 I know what I need to do and can do it 


\section{APPENDIX C \\ “An Investigation of Professional Development through Collaborative Experiences among Teachers"$$
\sim \text { Buddy System }
$$

\section{Buddy Buoy}

Meet with your buddy each Wednesday morning from 7:30-7:50 - Buoy Time

Purpose: encourage and pray for one another as educators (keep one another afloat)

\section{Process:}

- Keep a prayer journal

- Agree to be held accountable with a teaching responsibility - lesson plans, phone calls, grading, extra duty, or

- Plan for, review, and document observations (Buddy Watch)

- Pray together or agree to pray later (especially for classroom issues)

\section{Buddy Watch}

At least four times during the semester, watch your buddy teach for a class period.

Purpose: make observations that can be used to expand your teaching repertoire

Process:

- Observe only when invited

- Document (see attached forms)

- Be creative and try something new! 


\section{APPENDIX D}

\section{Buddy Watch}

To be completed by the observer

Observer:

Classroom Teacher:

Date of observation:

Class Period: $1 \begin{array}{lllllll}1 & 2 & 3 & 4 & 5 & 6 & 7\end{array}$

Answer at least one of the following:

What did I like?

What did I not understand?

What might I try to do myself? 


\section{APPENDIX E}

\section{Buddy System Progress Report}

To be reviewed with the principal after each semester

Teacher

Buddy Signature

Principal Signature

Date Reviewed

Complete the appropriate boxes.

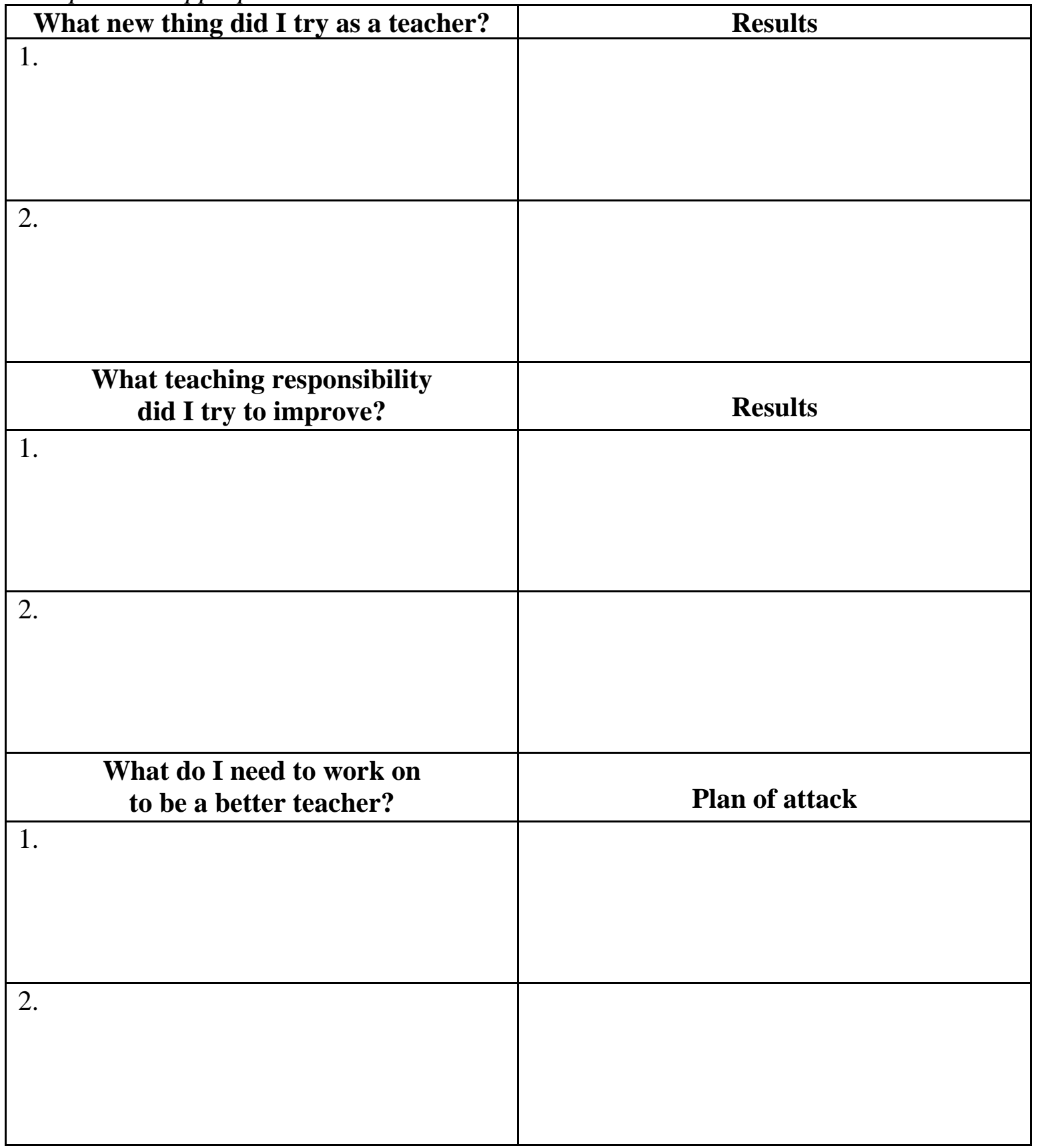




\begin{abstract}
APPENDIX F
Comfort and prosperity have never enriched the world as much as adversity has. - Billy Graham
\end{abstract}

Nearly all men can stand adversity, but if you want to test a man's character, give him power. - Abraham Lincoln

Tell me and I forget. Show me and I remember. Involve me and I understand. - Chinese proverb

Teamwork is the fuel that allows common people to attain uncommon results. - Andrew Carnegie

You become successful by helping others become successful. - Anonymous

Coming together is a beginning, staying together is progress, and working together is success. - Henry Ford

We offer others a chance to lighten their load when we say little and listen loudly. - Noah benShea

The greatest compliment that was ever paid me was when one asked me what I thought, and attended to my answer. - Henry David Thoreau

Communication does not begin with being understood, but with understanding others. W. Steven Brown

Talent is God-given. Be humble. Fame is man-given. Be grateful. Conceit is selfgiven. Be careful. - John Wooden

Trying to squash a rumor is like trying to unring a bell. - Shana Alexader

A pessimist sees the difficulty in every opportunity; an optimist sees the opportunity in every difficulty. - Sir Winston Churchill 
A teacher affects eternity; he can never tell where the influence stops. - Henry B. Adams

Set your affection on things above, not on things on the earth. - Colossians 3:2

Call upon Me in the day of trouble. - Psalm 50:15

I've had a lot of problems in my live and most of them never happened. - Mark Twain

We are given children to test us and make us more spiritual. - George F. Will

One cool judgment is worth a thousand hasty counsels. The thing to do is to supply light and not heat. - Woodrow Wilson

Cast all your anxiety on him because he cares for you. I Peter 5:7

How great is the love the Father has lavished on us, that we should be called children of God! - I John 3:1

My soul finds rest in God alone; my salvation comes from him. - Psalm 62:1

Praise the Lord, O my soul, and forget not all his benefits. - Psalm 103:2 


\section{APPENDIX G}

(Results provided are average scores)

Thanks for your participation in my school project his semester.

I need you help one more time in wrapping up this project. Please take a few minutes to answer the following:

Name

Approximate number of times you observed your buddy.

Approximate number of times you were observed by your buddy.

\section{Rank the following items in order as to your preferences for next semester:}

(1 is most desired)

Continue the peer observations with the same buddy (prayer partner).

Continue the peer observations but with a new buddy (prayer partner).

Keep the same buddy (prayer partner) but do peer observations with a teacher(s) of your choice.

Keep the same buddy (prayer partner), but no longer be expected to do any peer observations.

Scrap the system and on Wednesday mornings I would rather do the following to help me be a better teacher:

Final Buddy System Evaluation - overall the project has

Circle your choice

1

2

3

4

5

helped me to be a

better teacher

not helped me to be a better teacher

Final Comments: 


\section{APPENDIX H}

(Results provided are average scores)

Thanks for your participation in my school project his semester.

I need you help one more time in wrapping up this project. Please take a few minutes to answer the following:

Name

2.3 Approximate number of times you observed your buddy.

2.4 Approximate number of times you were observed by your buddy.

\section{Rank the following items in order as to your preferences for next semester:}

(1 is most desired)

2.5 Continue the peer observations with the same buddy (prayer partner).

3.3 Continue the peer observations but with a new buddy (prayer partner).

1.8 Keep the same buddy (prayer partner) but do peer observations with a teacher(s) of your choice.

2.8 Keep the same buddy (prayer partner), but no longer be expected to do any peer observations.

4.7 Scrap the system and on Wednesday mornings I would rather do the following to help me be a better teacher:

Final Buddy System Evaluation - overall the project has

Circle your choice- AVERAGE CHOICE WAS “2”

1

2

3

4

5

helped me to be a

better teacher

Final Comments: not helped me to be a better teacher 


\section{REFERENCES}

Ash, R. \& Persall, J. (2000). The principal as chief learning officer: Developing teacher leaders. NASSP Bulletin , 84, 15-22. Retrieved December 22, 2003 from Wilson Web.

Barth, R. (1990). Improving schools from within. San Francisco, CA: Jossey-Bass, Inc., Publishers.

Beatty, B. (1999). Teachers leading their own professional growth. Retrieved July 15, 2003, from Educational Resources Information Center.

Beerer, K. (2002). District carves out time for new teachers to learn. Journal of Staff Development, 23, 46-49. Retrieved December 22, 2003, Wilson Web.

Bennett, W. (Ed.). (1993). The book of virtues. New York, NY: Simon and Schuester

BenShea, N. (2002). Great quotes to inspire great teachers. Thousand Oaks, CA: Corwin Press

Bernardt, R, Hedley, C, Cattaro, G, Svolopoulos, V. (Eds.). (1998). Curriculum leadership: Rethinking schools for the $21^{\text {st }}$ century. Cresskill, NJ: Hampton Press, Inc.

Bryk, A. \& Schneider, B. (2003). Trust in schools: a core resource for school reform. Educational Leadership, 60, 40-44. Retrieved July 15, 2003, from Education Abstracts.

Bush, G. (2003). The school buddy system. Chicago, IL: American Library Association. Buzzell, S. (Ed.). (1998). The leadership Bible. Grand Rapids, MI: Zondervan Publishing House 
Calderon, M. (1999). Teachers learning communities for cooperation in diverse settings. Theory into Practice, 38, 94-99 Retrieved July 11, 2003, from Wilson Web.

Checkley, K. (1999). Learning from the masters. Association for supervision and curriculum development, 41, 1-3. Retrieved December 22, 2003, from Wilson Web.

Colvin, G. (1996). Teacher education for the 21st century: The agony and the ecstasy. American Secondary Education, 24, 17-22. Retrieved July 11, 2003, fromWilson Web.

Cruickshank, D. \& Haefele, D. (2001). Good teachers, plural. Educational Leadership, 58, 26-30. Retrieved July 2, 2003, from Wilson Web.

Curran, B. \& Goldrick, L. (2002). Mentoring and supporting new teachers. Retrieved July 11, 2003, from NGA center for best practices.

Dixon, F., Willis, R., Benedict, J., \& Grossman, E. (2001). Staff development: old dogs can learn new tricks. Teacher Educator, 36，219-232. Retrieved July 15, 2003, from Wilson Web.

Donaldson, G. \& Sanderson, D. (1996). Working together in schools: a guide for educators. Thousand Oaks, CA: A Sage Publications Company

Emihovich, C. \& Battaglia, C. (2000). Creating cultures for collaborative inquiry: new challenges for school teachers. International journal of leadership in education, 3 , 225-238. Retrieved December 22, 2003 fromWilson Web.

Foley, R., Skipper, S., Cowley, C., Angell, C. (1997). Self-perceived competence of general educators participating in collaboration activities: A survey of preservice 
educators. The Teacher Educator, 33, 112-123. Retrieved July 11, 2003, from Educational Resources Information Center.

Friend, M \& Cook, L. (2003). Interactions: Collaboration skills for school professionals. Boston, MA: Allyn and Bacon.

Fullan, M. (2001). Leading in a culture of change. New York, NY: Jossey-Bass publisher Ganser, T. (2002). Sharing a cup of coffee is only a beginning. Journal of Staff Development, 4, 23. Retrieved December 22, 2003, Wilson Web.

Ganser, T. (1999). Under their wing: Promises and pitfalls of mentoring. High School Magazine, 7, 8-13. Retrieved July 2, 2003, from Educational Resources Information Center.

Getz, G. (1997). Building up one another. Colorado Springs, CO: Chariot Victor Publishing.

Grottesman, B. (2000). Peer coaching for educators. Lanham, MD: Scarecrow Press, Inc.

Hawley, W. \& Rollie, D (Eds.). (2002). The keys to effective schools. Thousand Oaks, CA: Corwin Press

Hendrick, H \& Hendrick, W. (1995). As iron sharpens iron. Chicago, IL: Moody Press. Huling, L. \& Resta, V. (2001). Teacher mentoring as professional development. ERIC Clearinghouse on Teaching and Teacher Education, 4. Retrieved on December 22, 2003 from Educational Resource Information Center.

Johnson, M., Johnson, G. (1999). The insiders. Journal of Staff Development, 20, 27-29. Retrieved July 15, 2003, from Wilson Web. 
Kelehear, Z. (2002). Tell me what went well with you lesson, Sam. Journal of Staff Development, 23, 33-36. Retrieved December 22, 2003 from Wilson Web.

Kochan, F. \& Trimble, S. (2000). From mentoring to co-mentoring: establishing collaborative relationships. Theory into Practice, 39, 20-28. Retrieved December 23, 2003 from Wilson Web.

Koehler, M. (1996). When collegiality doesn’t work. The Clearing House, 69,167-168. Retrieved July 15, 2003, from Educational Resources Information Center.

Koehler, M \& Baxter, J. (1997). Leadership through Collaboration: Alternatives to the hierarchy. Larchmont, NY: Eye on Education, Inc.

Lieberman, A. (Ed.). (1988). Building a professional culture in schools. New York, NY: Teacher College Press.

Lieberman, A. \& Miller, L (Eds.). (2001). Teachers caught in the action: Professional development that matters. New York, NY: Teachers College Press

Lieberman, A., Miller, L. (1990). Teacher development in professional practice schools. Teachers College Record, 92, 105-118. Retrieved July 15, 2003, from EBSCO Research Databases.

Little, J. (1990). The persistence of privacy: Autonomy and initiative in teachers' professional relations. Teachers College Record, 91, 509-528. Retrieved July 15, 2003, from Academic Search Premier.

Lortie, D. (1975). Schoolteacher. Chicago, IL: The University of Chicago Press. Manouchehri, A. (2001). Collegial interaction and reflective practice. Action in Teacher Education, 22, 86-97. Retrieved July 15, 2003, from Wilson Web. 
Perry, E. (1997). Collaborative school improvement: An integrated model for educational leaders, 10. Retrieved on December 22, 2003 from Educational Rescources Information Center.

Peterson, K. (2000). Teacher Evaluation. Thousand Oaks, CA: Corwin Press Inc.

Phillips, T. \& Okholm, D. (2001). A family of faith. Grand Rapids, MI: Baker Academic Co.

Sandholtz, J. (2000). Interdisciplinary team teaching. Teacher Education Quarterly, 27, 39-54. Retrieved July 11, 2003, from Educational Resources Information Center.

Sergiovanni, T. (1994). Building community in schools. San Francisco, CA: Jossey-Bass Publishers

Smith, D. (1996). Peer coaches’ problems with videotape recording for teacher observation. Action in Teacher Education, 17, 18-27. Retrieved July 11, 2003, from Wilson Web.

Smyth, J. (2001). Critical politics of teachers'work: An Austrailian perspective. New York, NY: Peter Lang Publishing, Inc.

Sykes, G. (1996). Reform of and as professional development. Phi Delta Kappan, 77, 464-467. Retrieved July 15, 2003, from Educational Resources Information Center.

Thomas, G., Wineburg, S., Grossman, P., Myhre, O., \& Woolworth, S. (1998). In the company of colleagues: An interim report on the development of a community of teacher learners. Teaching and Teacher Education, 14, 21-32. Retrieved July 11, 2003, from Educational Resources Information Center. 
Walker, W. (1999). Collaboration: The faint of heart need not apply. Peabody Journal of Education, 74, 300-305. Retrieved July 11, 2003, from Educational Resources Information Center.

Warren, R. (2002). The purpose driven life. Grand Rapids, MI: Zondervan

Weasmer, J., Woods, A. (1999). Peer partnering for change. Kappa Delta Pi, 36, 32-34. Retrieved July 11, 2003, from Educational Resources Information Center.

Wineburg, S. \& Grossman, P. (1998). Creating a community of learners among high school teachers. Phi Delta Kappan, 79, 350-356. Retrieved July 11, 2003, from Educational Resources Information Center. 
VITA

Van Bryce Holloway grew up on his family’s farm in Union Grove, Wisconsin. He decided to follow Christ at the age of twelve primarily due to the Christian influences of his family and home church. After graduating from Union Grove Christian School in 1984, Van chose to continue his education at Cedarville College. By God's grace, Van was able to graduate from Cedarville College in 1988 with a B.A. degree in biology and an emphasis in secondary education. God then led Van to Xenia Christian Day School, located in Xenia, Ohio as a science teacher. In 1993, Dayton Christian Schools, Inc. assumed operation of what is now called Xenia Christian High School. During this transition, Van continued to serve as teacher, coach, and, for a time, athletic director. At the time of this project, Van is completing his $16^{\text {th }}$ year of teaching and coaching tennis at Xenia Christian High School.

Currently, Van and his wife Janell live in Xenia, Ohio. They have been blessed with four boys between the ages of seven and twelve. Van, along with his family, is active in several ministries at Emmanuel Baptist Church in Xenia. He regularly teaches at the County Juvenile Detention Center, is a church deacon, and leads a small group, adult Bible study. Furthermore, Cedarville University has given Van several opportunities to work as an adjunct instructor in the departments of math, science, and mediated instruction. 